Chapman University

Chapman University Digital Commons

Accounting Faculty Articles and Research

Accounting

$11-16-2018$

\title{
Ideological Diversity in Standard Setting
}

Jivas Chakravarthy

Follow this and additional works at: https://digitalcommons.chapman.edu/accounting_articles

Part of the Accounting Commons, Business Law, Public Responsibility, and Ethics Commons, Organizational Behavior and Theory Commons, and the Other Business Commons 


\section{Ideological Diversity in Standard Setting}

\section{Comments}

This is a pre-copy-editing, author-produced PDF of an article accepted for publication in Review of Accounting Studies in 2018 following peer review. The final publication is available at Springer via DOI: 10.1007/

s11142-018-9478-7.

\section{Copyright}

Springer 


\title{
Ideological Diversity in Standard Setting
}

\author{
Jivas Chakravarthy \\ Assistant Professor \\ Chapman University \\ Email: chakrava@chapman.edu
}

August 16, 2018

This paper is based on my dissertation at Emory University, which was a co-winner of the 2015 FARS Best Dissertation Award. I thank my committee - Shiva Rajgopal (Chair), Greg Waymire, Ilia Dichev, and Chris Rider as well as Dennis Beresford, Mengyao Cheng, Tom Clark, Stephen Deason, Ed deHaan, Peter Demerjian, Bob Herz, Kathryn Kadous, Paul Madsen, Melanie Millar, Karthik Ramanna, Anand Swaminathan, Roger White, Stephen Zeff, multiple anonymous referees, and workshop participants at Emory University, Georgetown University, Washington University in St. Louis, University of Minnesota, University of Toronto, London Business School, University of Chicago, Northwestern University, Boston College, Baruch College (CUNY), Dartmouth College, Harvard Business School, Carnegie Mellon University, Chapman University, and the Southern California Accounting Research Forum for their comments and suggestions. I thank Jenna McAuley, Yuepin (Daniel) Zhou, and Chris Hauber for their excellent research assistance, and Goizueta Business School, the Sheth Research Fellowship, and the Argyros School of Business and Economics for funding. I also thank Stacey Sutay (FASB) and John Pappas (FAF) for their assistance in providing documents from their Public Record. All errors are my own. 


\title{
Ideological Diversity in Standard Setting
}

\author{
August 16, 2018
}

\begin{abstract}
I explore whether the level of ideological diversity among Financial Accounting Standards Board (FASB) members has declined since the emergence of their conceptual framework. I analyze votes made by FASB members on Statements of Financial Accounting Standards and compare them to comment letters submitted by constituent sponsoring organizations. I demonstrate that, relative to the Pre-CF regime (1973-1986), FASB members' voting positions in the $C F$ regime (1987-2007) are (i) less like their constituent sponsors and (ii) more like one another. The former result is primarily attributable to differences between FASB members with auditor and preparer backgrounds and those groups' sponsors. Both of these shifts are associated with standards increasing accounting relevance; in the $C F$ regime, standards that increase relevance likely do so because of the framework's broad focus on decision usefulness. I document a significant increase in sponsors' dissent in the $C F$ regime, and regression analysis indicates that variation in standards' authoritative references to the conceptual framework accounts for all of this increase. Lastly, from 1996-2007, all but one dissenting vote by FASB members on fair value standards explicitly argues for an even greater use of fair values, while none argue for less use. To the extent FASB members' individual ideologies influence their voting positions, the evidence is consistent with a decline in the level of ideological diversity among FASB members in the $C F$ regime.
\end{abstract}

JEL Classification codes: D72, G18, M48

Keywords: Accounting standards; Conceptual framework; Financial Accounting Standards Board (FASB); Ideology; Standard setting

Data availability: The data used in this study are available from the sources identified herein. 


\section{INTRODUCTION}

In this study, I investigate a potential long-term consequence of the Financial Accounting Standards Board's ("FASB" or "the Board") conceptual framework ("CF" or "the framework"). The framework was central to the FASB's creation, as one of the items on their initial agenda was a project to establish broad standard setting guidelines (FASB 1973) that evolved into the CF. Intended to provide the Board with a cohesive system of objectives and fundamentals to use in setting standards, the framework was to guide the FASB in part by prohibiting alternatives that violate it, thereby narrowing the range of alternatives for the Board to consider (FASB 1976). Baxter (1962) posits that one consequence of authority declaring that any one view of accounting is better than the others is that, in the long run, it can "narrow the scope for individual thought and judgment." Kothari et al. $(2010,36)$ call for research to address "what institutional features of standard setting might help reduce the effect of ideology on standard setting?" In this spirit, I explore whether the conceptual framework has served to embed the effect of ideology in standard setting by causing a decline in the level of ideological diversity among standard-setters.

An ideology is a collection of normative beliefs and values held by an individual or group (Honderich 2005). Clearly, members of deliberative bodies such as the FASB are not motivated solely by their personal ideological beliefs; they face complex and competing motivations while making consequential decisions. Nevertheless, the dominant political science view is that U.S. Supreme Court justices' votes primarily reflect their personal "ideological attitudes and values" (Segal and Spaeth 2002). Similarly, FASB members' ideologies likely influence their voting positions (assent or dissent) on Statements of Financial Accounting Standards ("SFASs" or "standards"). To the extent this is the case, ceteris paribus, a decline in dissent implies fewer opposing viewpoints and, therefore, a decline in ideological diversity. 
Ex post, it may seem obvious to some that narrowing the set of acceptable accounting will ultimately narrow the ideologies of standard-setters. Ex ante, however, the FASB held dual goals of developing a conceptual framework (AICPA 1973) and promoting a diversity of views and backgrounds (AICPA 1972). As such, it seems unlikely there was an intent for the CF to reduce ideological diversity. Indeed, Miller et al. (1994, 20-21) note that the FASB was formed in part because its predecessors "did not appear to provide an equal opportunity for all interested groups to participate in (and to affect the outcome of) the standards-setting process."

To determine when the FASB began implementing the framework, I review each standard and identify every authoritative reference to the CF. I find a sharp increase in such references shortly after the issuance of SFAS 91 and distinguish the CF regime (SFAS 92-160, 1987-2007) from the Pre-CF regime (SFAS 1-91, 1973-1986) in order to evaluate possible effects of the framework. I then note that the FASB has linked decision usefulness, which they state is the broad focus of the $\mathrm{CF}$, to their emphasis on the relevance of information to investors and creditors (Johnson 2005). Therefore, in order to link standards to the framework, I utilize Allen and Ramanna (2013) metrics to identify standards that increase accounting relevance.

A key goal driving the FASB's initial institutional structure was to increase the diversity of views and backgrounds involved in the standard setting process (AICPA 1972, 57-60). This structure operated as follows: constituents were divided into groups - auditors, financial statement preparers, financial statement users (e.g. investors, financial analysts), accounting academics, and government regulators; each constituent group was represented by sponsoring organizations (e.g., auditors were represented by the AICPA); the sponsors elected Trustees of the Financial Accounting Foundation (FAF); and the FAF Trustees elected FASB members. I compare FASB members' votes on standards to positions taken by sponsors in comment letters 
to Exposure Drafts relating to those standards. Utilizing sponsors' positions not only provides a meaningful point of comparison for FASB positions, it also provides a control for endogenous standard-specific characteristics that might affect the rate of dissent - for example, if standards proposed under one regime are inherently more controversial than under the other regime.

In total, I compare 762 FASB votes on 159 standards to the position of each member's sponsoring organization(s). Using a difference-in-differences design, I demonstrate that, relative to the Pre-CF regime, in the $C F$ regime FASB members vote (i) less like their sponsor(s) and (ii) more like one another. (In supplemental analysis, I discover that the former result is primarily attributable to differences between FASB members with auditor and preparer backgrounds and those groups' sponsors.) I then create a variable to measure the diversity of FASB members' positions relative to their sponsors on each standard. I use multivariate analyses to confirm the finding that there was a decline in the diversity of FASB members' voting positions in the $C F$ regime, both independently (i.e., within the Board itself) and relative to their sponsors.

If this decline is a consequence of the framework, diversity should be lower on those standards associated with it. I extend the multivariate analyses and document that the observed decline in the diversity of FASB positions (both independently and relative to their sponsors) is associated with standards that increase accounting relevance. In the $C F$ regime, standards that increase relevance likely do so because the FASB reinforced the framework's focus on decision usefulness. I then use the sponsors' comment letter positions to develop a measure of 'constituent dissent,' and note an increase in sponsor dissent in the $C F$ regime. Regression analysis indicates that the observed increase in standards' authoritative references to the framework accounts for all of the increase in sponsor dissent. These results confirm a link between the decline in diversity of FASB voting positions and standards associated with the CF. 
In my primary analysis, I do not differentiate the reasons behind each dissent, so it is possible that I mischaracterize some dissenting members' positions. I read and code dissenting explanations on fair value standards, which I identify via an Allen and Ramanna (2013) metric. This allows me to identify whether, among other reasons, the dissenting member opposes because they disagree with the use of fair values (what I term "outside dissent") - or whether they oppose because the standard does not implement enough fair value accounting ("inside dissent"). In periods with low ideological diversity, we would expect to see relatively limited 'outside' dissent. Across twenty-two fair value standards from SFAS 125 to SFAS 160, encompassing 149 votes in total, I find zero 'outside' dissents and only one dissent that does not explicitly call for an even greater use of fair values. Across these standards, I identify 117 sponsors' positions and document 42.5 dissents. This demonstrates very little diversity among FASB members' positions on the issue of fair value accounting in the $C F$ regime.

I perform a series of robustness tests. I first perform alternate tests in which I compare each FASB vote to the average position of all constituent groups' sponsors. This demonstrates that my primary results are not driven by temporal changes in constituent group representation on the Board (e.g., fewer auditor members in the $C F$ regime). I then show that there is no significant temporal change in the FASB's length of deliberation in response to unpopular Exposure Drafts. As such, it is unlikely that they responded to unpopular standards with more substantive changes in the $C F$ regime than in the Pre-CF regime. Lastly, I show that the results are robust to (i) removing the standards deemed least significant by the FASB's constituents, (ii) using earlier 'break' points to divide the sample, and (iii) removing any individual observation.

I document a significant decline in the diversity of voting positions among FASB members during the $C F$ regime, and demonstrate links between this decline and standards 
associated with the conceptual framework. While I cannot specify a precise causal mechanism for this effect, to the extent FASB members' individual ideologies influence their voting positions, the overall evidence is consistent with the conceptual framework causing a significant long-term decline in the level of ideological diversity among standard-setters.

Recent surveys have highlighted ideology theory - that standards are jointly determined by standard-setters' ideologies and interest-group lobbying - as a useful model of standard setting (Kothari et al. 2010; Gipper et al. 2013; Ramanna 2015). I contribute to this literature by highlighting the role of ideological diversity, as ideology may be less influential when standardsetters' ideologies are relatively diverse, and lobbying efforts from diverse interest groups may be less influential when standard-setters' ideologies are more narrowly dispersed. If so, then perhaps one consequence of the FASB implementing its framework is that interest-group lobbying carried relatively less influence during the $C F$ regime than during the Pre-CF regime.

I am not aware of any prior studies on the ideological diversity of standard-setters, or that empirically examine the long-term consequences of the FASB's conceptual framework. Allen and Ramanna (2013) evaluate how FASB members' personal characteristics influence the nature of standards. Numerous studies empirically test the link between lobbying on proposed accounting standards and changes subsequently made to those standards, both in the U.S. (Puro 1984; Brown and Feroz 1992; Buckmaster et al. 1994; Ramanna 2008) and abroad (McLeay et al. 2000; Hansen 2011). Other studies evaluate voting for evidence of coalition formation (Newman 1981a, 1981b; Selto and Grove 1983; Moody and Flesher 1986) and find that voting power is not concentrated within repeated coalitions.

Prior research does provide an alternate perspective on certain changes during the $C F$ regime. Healy and Wahlen (1999) link the rise in fair values to the S\&L crisis in the late 1980's. 
The governmental response to this crisis (Zeff 2003, 272-273) may have led to the addition of FASB members with financial services backgrounds (Allen and Ramanna 2013). Ramanna (2013) attributes the rise of fair values to the inclusion of these members, while Jiang et al. (2017) note that financial instruments were the most frequent topic for standards during this period. This process might have empowered the financial services industry, and, indeed, I find financial statement user sponsors most favored the FASB's direction (Young 2006). While this composite account may help explain certain changes - like the increased use of fair values - it does not explain the observed decline in the diversity of FASB members' voting positions. Perhaps, in addition to these changes, some external threat caused members to vote with greater unanimity to demonstrate strength in order to protect the institution (Rohde 1972; Newman 1981a). However, the observed increase in inside dissent runs counter to this explanation.

On the other hand, perhaps FASB members in the $C F$ regime vote less like their sponsors and more like one another due to any number of changes unrelated to the framework that differentially affected the standard setting environment in each regime. For example, perhaps changes to the Board's due process caused members to be less sensitive to the views of their constituents in the $C F$ regime. However, alternative explanations of this type cannot reconcile why the observed patterns are more pronounced on standards associated with the framework.

To summarize, the evidence I present in this study is consistent with the conceptual framework causing a long-term decline in the level of ideological diversity among standardsetters. Moreover, while I cannot rule out alternative explanations for each individual finding, it is difficult for any single alternate explanation to reconcile all of the evidence. As such, I hope to amplify the Kothari et al. (2010) call for research to more clearly specify the factors that appear to have institutionalized ideology in U.S. standard setting. 


\section{BACKGROUND AND HYPOTHESES}

\subsection{Background: Ideological Beliefs}

An ideology is a collection of normative beliefs and values held by an individual or group (Honderich 2005). Differing ideological beliefs about accounting concepts and methods - for example, support for either the income statement or balance sheet approach (Gipper et al. 2013) - can drive competing preferences on accounting standards.

At present, we know very little about what motivates standard-setters (Kothari et al. 2010). In addition to their ideology - and beyond the facts of the standard up for debate standard-setters' decisions are likely a function of many competing motivations, including concerns about their reputation, career, and influence, the preferences and influence of their constituents and other standard-setters, and the broader institutional context.

Similarly, U.S. Supreme Court justices face complex motivations. Nevertheless, the 'attitudinal' approach (Segal and Cover 1989; Segal and Spaeth 2002) - that justices' votes largely reflect their personal ideological attitudes and values - has emerged as the dominant political science view. Indeed, while the 'strategic' approach (which focuses on the effect of strategic behavior and institutional context) is often framed as a competing alternative (e.g., Martin and Quinn 2002), its authors acknowledge that ideology is the primary factor determining justices' decisions (Epstein and Knight 1998). Therefore, political science informs us that a standard-setters' personal ideology likely has a significant influence on their voting decisions. As such, I use FASB members' voting positions as a proxy for their ideological beliefs.

\subsection{Background: Institutional Structure}

The FAF and FASB were created following a period of "unprecedented stress" on the accounting profession that created an urgent need for improving accounting standards (AICPA 
1972, 3-4). In this environment, one of the FASB's founding objectives was to increase the diversity of views and backgrounds involved in the standard setting process. This was accomplished in part by providing statutory authority to 'sponsoring organizations' representing five constituent groups (Zeff 1978; Gore 1992, 141-151), as illustrated in Figure 1. ${ }^{1}$

Historically, members of these organizations (via a separate group of "Electors") met to collectively elect new FAF Trustees from a pool of individuals nominated by the organizations. ${ }^{2}$ The FAF Board of Trustees then selected FASB members. As such, during the period covered in this study, the constituent sponsors held indirect authority to select FASB members.

This authority was statutory, included in the FAF's by-laws and subject to change as groups exchanged influence through time. For example, the 1987 FAF by-laws dictated that the sixteen Trustees were to include four auditors, three preparers, two users, one academic, three government regulators, and three at-large Trustees. ${ }^{3}$ Similarly, the Board's composition has historically reflected informal quotas, subject to change over time; in 1987, the seven members included three auditors, two preparers, one academic, and one government regulator.

\subsection{Background: Conceptual Framework}

\subsubsection{Demand for an accounting framework}

One of the founding objectives of the FASB's predecessor (the Accounting Principles Board, or APB) was to determine basic postulates and broad principles of accounting, and they were widely perceived to have failed at the task (Moonitz 1974; Zeff 1999). In 1970, the APB

\footnotetext{
${ }^{1}$ I additionally confirm information in section 2.1 through review of the FAF's historical by-laws, which I obtained from the FAF by request in 2013. They provided twelve such documents from the Public Record.

2 This describes the process until 2002, when the process changed for every group (except for the Government), such that the existing FAF Board of Trustees elected new Trustees from candidates provided by the sponsors. This changed again in 2008 to fully remove all formal authority of the non-Government sponsors to elect FAF Trustees FAF (2008). The latter change did not take effect until after all standards covered in this study were issued.

${ }^{3}$ Little research has been done over the FAF's actions, perhaps because some of their activities - including meetings to determine the selection of FASB members - are conducted in private (Miller et al. 1994).
} 
issued Statement No. 4 ("Basic Concepts and Accounting Principles Underlying Financial Statements of Business Enterprises"); however, it was seen as a disappointment, and did little to reduce the demand for a deductive framework (Gore 1992).

The APB was the target of both dissatisfaction from constituents and oversight pressure from the SEC and Congress. The APB struggled to provide detailed guidance on divisive topics - as some members were content to describe generally accepted practices - and were criticized for the diversity of observed practice for similar transactions and circumstances. Due to ideological differences on fundamental issues, it was difficult to generate consensus on controversial topics. ${ }^{4}$ As such, much of the APB's guidance reflected compromises between opposing points of view (Dopuch and Sunder 1980), so standards lacked "coherence and logic" (AAA 1971) and were not always broadly accepted (Horngren 1973). Also, the APB approached each issue on a standalone basis (Gellein 1986), sometimes leading to internally inconsistent standards (Chatov 1975). The framework provided a means to address many of these issues.

\subsubsection{The 'conceptual framework regime'}

The framework is a collective of Concepts Statements (CONs) issued over a number of years, though the prevailing belief (Solomons 1986; Agrawal 1987; Gerboth 1987) was that the issuance of CON 6 in December 1985 completed the CF. To determine when the FASB began implementing the framework, I document every authoritative reference in standards to the $\mathrm{CF}$, as follows. I download PDFs of all original pronouncements from the FASB website, search the text of each standard (i.e., the numbered paragraphs and footnotes) for "concept," review each item, and document three types of explicit references. First, authoritative references to APB Statement No. 4 (once the initial search for "concept" identifies one reference to APB No. 4, I

\footnotetext{
${ }^{4}$ See Zeff $(1971,134-236)$ as a reference for the preceding portion of the paragraph.
} 
search "No. 4" to identify additional references). Second, references that the Board was limited in some way, or the scope of the standard was affected, because the CF was not yet complete. ${ }^{5}$ Third, authoritative references to the CF (either to individual CONs or to the "conceptual framework"); this excludes both (i) mentions that constituent respondents referenced the CF and (ii) basic descriptive (i.e., non-authoritative) references to the CF. I consolidate multiple citations within a single numbered paragraph into one 'reference.'

The data, illustrated in Figure 2, indicate a sharp increase in the volume of CF references starting with SFAS 93, issued in October 1987. Since SFAS 92 was also issued in October 1987 and was the first standard issued under a new Chairperson, I use it as a 'break point' and define SFAS $1-91$ as the Pre-CF regime, with SFAS 92 the start of the $C F$ regime. ${ }^{6}$ After splitting the data in Figure 2 by regime, only one value in the $C F$ regime (associated with SFAS 104) is lower than the maximum value in the Pre-CF regime (SFAS 79). The data, therefore, indicate a discrete break in implementation of the conceptual framework around this time.

\subsection{Hypotheses}

One element of the FASB's founding mission was to develop conceptually consistent standards, while another was to diversify the voices and backgrounds involved in the standard setting process. Is it possible that these goals are in conflict - that one consequence of institutionalizing accounting standard setting is that it can lead to a narrowing of thought?

Referring to the CF as a 'constitution,' the FASB $(1976,6)$ noted "it will narrow the range of alternatives to be considered by the Board because some alternatives will clearly be

\footnotetext{
${ }^{5}$ For example, from SFAS 48: “...the Board may wish to evaluate the standards in this Statement when its conceptual framework project is completed" (FASB 1981, para 17).

${ }^{6}$ The institutional structure central to this study, described in Section 2.2, ended in 2008; see Note 2. Further, in 2008 the first Exposure Draft for an update to the FASB's CF via the FASB-IASB convergence project was issued (FASB 2008). The convergence project resulted in two updates in 2010 before the project ended in 2014.
} 
'unconstitutional.'” Baxter (1962) argues that following such a direction is, ultimately, likely to narrow the scope for individual thought and judgment. On freedom of thought (pp. 420-421):

\begin{abstract}
'Freedom'...means the absence... of benevolent authority that makes us respectful to some ideas and hostile to others. Man should be able to think freely and without bias, so that the stream of new ideas can flow strongly; and he should be able to discuss and experiment freely and without bias, so that all ideas can be criticised and tested with rigour. If authority intervenes...by giving its imprimatur to some favourite idea...the chances of progress are lessened. Men cease to think so freely.... and therefore the stream of new ideas dries up. They cease to discuss and experiment so freely...criticism loses its edge, and ideas are not put to a stern test. (emphasis original)
\end{abstract}

Baxter's argument provides the motivation for this study, but it provides neither a

mechanism nor a testable theory. Rather, I explore one potential consequence of his prediction: whether the CF has helped reduce the level of ideological diversity among standard-setters. ${ }^{7}$

This requires addressing two distinct questions. The first question is, has ideological diversity declined during the $C F$ regime? As this study is exploratory, all hypotheses are in the null form.

Hypothesis 1a: There is no change from the Pre-CF regime to the $C F$ regime in the diversity of FASB members' voting positions.

As the sponsoring organizations were selected in part to reflect a diversity of views and backgrounds, they represent an ideal point of comparison against which to measure the effect of the framework. As such, I compare FASB positions to positions taken by their sponsors.

Hypothesis $1 \mathrm{~b}$ : There is no change across regimes in the diversity of FASB members' voting positions relative to the diversity of their sponsors' positions.

The second question to be addressed is, if ideological diversity declined during the $C F$ regime, is the $\mathrm{CF}$ associated with the decline? While $\mathrm{H} 1 \mathrm{a}$ and $\mathrm{H} 1 \mathrm{~b}$ indirectly address this question, I address this question more directly with Hypotheses $2 \mathrm{a}$ and $2 \mathrm{~b} .^{8}$

\footnotetext{
${ }^{7}$ Baxter (1962) does not reference the idea of a conceptual framework. However, in a follow-up article Baxter stated of the FASB's then in-progress CF that "such a super-standard of ultimate principles would be a fearsome extension" towards the future direction he was arguing against (Baxter 1981, 6). Others have presented similar arguments that detailed standards can discourage professional debate and experimentation (Sunder 2010).

${ }^{8} \mathrm{H} 1 \mathrm{a}$ and $\mathrm{H} 1 \mathrm{~b}$ provide some evidence towards this because the Pre-CF/CF distinction is not just an arbitrary, circumstantial 'break' in time - the data underlying Figure 2 provide evidence of a systematic difference in standards across regimes that directly relates to the framework itself.
} 
Hypothesis $2 a(2 b)$ : Variation across regimes in the diversity of FASB members' voting positions (relative to the diversity of their sponsors' positions) is unrelated to standards that are associated with the framework.

It is possible for individuals who oppose a standard to hold diametrically opposed positions on its underlying concepts. That is, one might fundamentally disagree with the ideas a standard implements ('outside' opposition), while another might oppose because the standard does not go far enough to implement the ideas ('inside' opposition). ${ }^{9}$ If ideological diversity declined during the $C F$ regime, and this was associated with the $\mathrm{CF}$, one consequence would be an increase in the rate of 'inside' opposition on standards associated with the framework.

Hypothesis 3: On standards associated with the framework, there is no change across regimes in the rate of 'inside' opposition as a percentage of all opposition.

\section{EMPIRICAL DESIGN}

\subsection{Empirical Approach}

\subsubsection{Identifying the positions of FASB members and their sponsoring organizations}

As described earlier, I use the voting positions of FASB member $i$ as a proxy for their ideological beliefs. On a given standard, these positions are assent $\left(P O S_{i}=1\right)$ or dissent $\left(P O S_{i}=\right.$ 0). This implies that, ceteris paribus, a Board voting 7-0 in favor of a standard is less ideologically diverse than one voting 5-2. However, standard-specific characteristics are also likely to affect the rate of dissent; some standards address highly controversial topics, while some others simply defer the effective date of prior standards. To address this, I compare FASB votes to the positions of the FASB's sponsors, thereby controlling for endogenous shifts in the types of standards proposed in each regime that might affect the rate of dissent. I identify the position taken by the sponsor(s) for each member's constituent group as follows.

\footnotetext{
${ }^{9}$ The initial U.S. standard setting body, the AICPA's Committee on Accounting Procedure, began publishing dissenting arguments in 1939 in order to distinguish between these two types of opposition (Zeff 1971, 138).
} 
I first identify every comment letter (CL) submitted by every sponsor to the final Exposure Draft (ED) relating to SFAS 1 through SFAS 160. ${ }^{10,11}$ (This represents 163 total standards, since the set is inclusive of revisions: SFAS 132R, 123R, and 141R). I classify the CL position of sponsor $m$ into five categories, as illustrated in Figure 3: strongly oppose $\left(P O S_{m}=0\right)$, lean oppose (0.25), neither support nor oppose (0.5), lean support (0.75), and strongly support $\left(P O S_{m}=1\right) .{ }^{12}$ When a sponsor submits more than one comment letter, I combine all letters into one document from which I identify $P O S_{m}$. Finally, I measure the position of constituent group $j$ $\left(P O S_{j}\right)$ on standard $t$ as the average position taken by that group's sponsor(s) $m$.

Both myself and a research assistant (RA) independently coded each CL based upon a random order of standards. The RA is a former accounting PhD student who was not informed about the topic or objectives of this study. I retained all data where our initial codes aligned. For letters where our codes differed, the RA and I exchanged notes about the rationale behind our decisions. Then, the RA considered the evidence and determined the final category for all letters. The weighted kappa (inter-coder reliability) between the initial two sets of codes was

\footnotetext{
${ }^{10}$ Typically, each sponsor has a committee specifically designed to interact with the FASB that prepares these comment letters. In fact, the signatories of the sponsors' CLs include ten individuals who later became Board members, including at least one member from each of the four major constituencies. Starting from the first signatory selected onto the Board, this represented ten of the next twenty-eight FASB members, indicating that the signatories of sponsors' CLs are likely one of the best sources of prospective FASB members.

${ }^{11}$ An Exposure Draft is "essentially a pro forma final document" that must be published for all projects that lead to an standard (Miller et al. 1994, 73). The FASB is supposed to incorporate only minor changes from an ED into the final standard; otherwise, they are to issue another ED for public review. As such, for each standard, I use comment letters submitted on the final ED. I address potential confounds arising from this issue in section 4.4.3.

The FASB's due process procedures have undergone numerous changes in order to balance standard setting timeliness with sufficient constituent outreach (Van Riper 1987). If the net effect has increased (decreased) constituent outreach prior to the ED stage, they may lead FASB positions to converge with (diverge from) sponsors' positions in the $C F$ regime, relative to the Pre-CF regime. Therefore, due process changes that are unrelated to the $\mathrm{CF}$ are potential confounds, as they may drive spurious results for $\mathrm{H} 1 \mathrm{a} / \mathrm{H} 1 \mathrm{~b}$. I address this matter in section 5.1.1.

${ }^{12}$ In a U.K. study, Georgiou (2004) finds that firms' use of unobservable lobbying in the standard setting process is significantly associated with their use of comment letters. Further, a U.S. study finds a strong complementary association between various forms of lobbying by interest groups (Ansolabehere et al. 2002). Therefore, positions stated within comment letters are likely to be associated with sponsors' preferred positions.
} 
0.64. Further, $95 \%$ of the initial codes (502 out of 528) either named the identical category or were within one adjacent category. A supplementary internet appendix includes the instructions provided to the RA, as well as examples of comment letter language within each category.

I am unable to "match" a FASB vote to the position of their associated sponsor(s) if they do not submit a CL on the related ED. When this occurs, I drop the observation from the "matched sample."13 I drop the Government constituency because their sponsors (GFOA and NASACT) submitted CLs on EDs for only two standards. I match votes from 159 out of 163 standards, and match a total of 762 constituent positions out of a pool of 1,011 FASB votes. I further illustrate this process by using SFAS 87 ('Employers' Accounting for Pensions") as an example. Seven FASB members voted on SFAS 87 - three auditors, one preparer, one user, one academic, and one government regulator. Comment letters to the final ED were received from the AICPA, FEI, IMA, CFA Institute, and AAA. These letters were coded as described above. Finally, six FASB votes are matched to sponsors' positions: the three auditors to the AICPA position, the preparer to the average of the FEI and IMA positions, the user to the CFA Institute position, and the academic to the AAA position. ${ }^{14}$

Appendix 1 provides detail on all key variables in this study. Appendix 2 provides data on all positions extracted from sponsors' comment letters (i.e., all $P O S_{m}$ ).

\footnotetext{
${ }^{13}$ I expect sponsors will submit CLs when the benefit of doing so exceeds the cost. Therefore, the set of comment letters I observe for each sponsor likely represents those standards that have meaningful priority to that organization, while the standards on which no letter is submitted are likely immaterial.

While the sponsors represent an ideal comparison group, this process does not represent a clean control match - as in a controlled laboratory experiment - and I do not imply this by using the term 'matched sample.'

${ }^{14}$ I aggregate votes for each standard (rather than analyzing each individual vote) to identify the positions of the Board as a whole, because the FAF collectively elects FASB members (i.e., sponsors do not select their own 'representative'; see section 2.1). Further, I match each member's vote to their sponsor(s) position (rather than to the average sponsor position) because I expect the Board's composition to be a function of each constituent group's relative influence at that time. That is, I do so in order to control for changes over time in the relative influence of each constituent group. In supplementary analysis, I re-perform hypothesis tests using an alternate measure in which I match each FASB vote to the average constituent group position; see section 4.4.2.
} 


\subsubsection{Measuring the diversity of positions taken by the FASB}

I measure the diversity of FASB members' positions on a standard by the rate of dissenting votes. I develop a variable, Representativeness $\left(R_{t}\right)$, to measure the diversity of FASB positions relative to sponsors' positions. $R_{t}$ measures the extent to which FASB members' positions on standard $t$ (the sum of $P O S_{i}$ on matched votes) aligns with the position of sponsors (the sum of $P O S_{j}$ ), and is structured such that 'perfect' representativeness leads to a value of 1.0 (see equation 1) ${ }^{15}$ If there is a decline across regimes in the diversity of FASB positions, a decline in $R_{t}$ demonstrates a decline in the diversity of FASB positions relative to their sponsors.

$$
R_{t}=1-\frac{\left|\sum_{\mathrm{j}} P O S_{j, t}-\sum_{\mathrm{i}} P O S_{i, t}\right|}{n_{i, t}}
$$

$\operatorname{POS}_{j, t}\left(P O S_{i, t}\right)$ represents the position of constituent group $j$ (FASB member $i$ ) on standard $t$, while $n_{i, t}$ represents the total number of matched FASB member votes on $t$. I drop all standards with fewer than two matched votes. With this restriction, $R_{t}$ is available for 153 out of a possible 163 standards. See Appendix 3, where I provide all $R_{t}$ values.

\subsubsection{Identifying standards associated with the CF}

As described in section 2.2.2, I have collected data on the number of times each standard cites the framework for authoritative guidance. Because this data is skewed, I calculate the variable $C F \_R e f s$ as the log of $[1+$ (the \# of authoritative references to the $\mathrm{CF}$ ) $]$. See Appendix 3, where I provide all $C F \_R e f s$ values. While this variable provides a very clear association between each standard and the CF, FASB members jointly determine (i) whether and how often

\footnotetext{
${ }^{15}$ I use SFAS 87 as an example to explain the intuition behind the metric. There were six matched FASB votes on SFAS $87\left(n_{i, t}=6\right)$, three assents and three dissents $\left(\sum P O S_{i, t}=3\right)$. The matched constituent positions were 0.5 , 0.5, $0.5,0.125,0.75$, and $0.75\left(\sum P O S_{j, t}=3.125\right)$. Therefore, the numerator is equal to 0.125 , the quotient is equal to 0.02 , and $R_{t}$ is equal to 0.98 , indicating strong alignment between the FASB and its sponsors.

I utilize a difference-of-sums construction (rather than a sum-of-differences) to identify the positions of the Board as a whole because the FAF collectively elects FASB members (see Note 14).
} 
to cite the CF and (ii) how they vote. Because of this endogeneity, I cannot use regression techniques to measure the marginal effect of $C F \_R e f s$ on the diversity of FASB positions.

Therefore, I seek an additional method to associate standards to the framework. The FASB has stated that decision usefulness (i.e., user primacy) is the broad focus of its framework (Johnson 2004) and that this represented a "fundamental change in attitude" toward the purpose of financial statements (Storey and Storey 1998, 71). While incorporating this new approach, the FASB has particularly emphasized the relevance of information to investors and creditors (Johnson 2005), and during the $C F$ regime it has issued many standards perceived to increase relevance (Allen and Ramanna 2013). Interestingly, standard-setters had long recognized the importance of accounting relevance; APB Statement No. 4 declared relevance to be the primary qualitative objective of financial accounting, and its description is nearly identical to the framework's description of relevance as a fundamental recognition criteria. ${ }^{16}$

While relevance was an established accounting concept, in the Pre-CF regime FASB standards did not frequently cite conceptual authority (either APB 4 or CONs; see Figure 2). Therefore, standards that increase accounting relevance in the $C F$ regime provide a relatively clean association with the framework. That is, relative to standards increasing relevance in the Pre- $C F$ regime, standards that increase relevance in the $C F$ regime likely bear that characteristic because the FASB reinforced the framework's focus on decision usefulness.

Allen and Ramanna (2013) provide two metrics, inc_relv and Manual_inc_relv, which measure the extent to which the Exposure Draft relating to each standard increases relevance. The inc_relv metric derives from a textual analysis of comment letters provided by Big 8/6/5/4

\footnotetext{
${ }^{16}$ APB No. 4: Relevant information "bears on the economic decisions for which it is used" (APB 1970, para 88). CON 5: Relevant information "is capable of making a difference in user decisions" (FASB 1984, para 63).
} 
auditors. ${ }^{17}$ The Manual metric is derived from a manual assessment from two independent reviewers, who develop a count variable with six values identifying various categories of fair value usage (in which a value of zero indicates no use of fair values). I develop an indicator variable, Inc_Relv, which equals one if either of the Allen and Ramanna (2013) relevance measures is greater than zero. This variable, therefore, identifies standards that either contemporaneous assessors (Big 8/6/5/4 audit firms) or modern assessors (independent reviewers) perceive as increasing accounting relevance.

\subsection{Hypotheses $1 a$ and $2 a$}

I test hypotheses 1a and 2a by estimating variations of equation 2 in a cross-sectional regression, with each observation reflecting a standard, and I use a Tobit regression because the dependent variable is left-censored at zero. ${ }^{18}$

$$
\begin{aligned}
& \text { FASB Dissent } t=\alpha+\lambda_{1} * \text { Pre-CF } F_{t}+\lambda_{2} * \text { Inc_Relv } t_{t}+\lambda_{3} * \text { Inc_Relv } * \text { Pre }-C F_{t}+ \\
& \lambda_{4} * \text { AvgTenure }_{t}+\lambda_{5} * \text { Supermajority }_{t}+\varepsilon
\end{aligned}
$$

FASB Dissent is the dissent percentage on each standard (total dissents $\div$ total votes).

Pre-CF is an indicator variable equal to one when the standard is issued in the Pre-CF regime. Inc_Relv identifies standards increasing accounting relevance. AvgTenure is the log of the average number of standards the members have voted on as of (and inclusive of) standard $t$. It is included as a control variable because Allen and Ramanna (2013) identified member tenure as a determinant of standard setting outcomes. Supermajority is an indicator variable equal to one

\footnotetext{
${ }^{17}$ This is done via the following process. First, all uses of the word stem "relevan" are extracted from each letter. Second, an RA assesses whether each reference is used in a positive context, or if the usage is irrelevant. Finally, the measures are determined based on the position within the letter of the first positive reference, such that the value of inc_relv is higher the earlier the first reference appears.

${ }^{18}$ Results for all specifications using Tobit regressions (i.e., equation 2 in Table 3 and equation 4 in Table 5) are qualitatively unchanged when estimated using OLS.
} 
when a standard is issued under a required supermajority vote. ${ }^{19}$ As simple majorities are not possible under such regimes, I expect this variable to be negatively related to dissent percentage.

Because the level of analysis is a standard, the output is produced by a combination of FASB members. As such, I partition the population of standards into those created by unique combinations of FASB members, and cluster standard errors by combination. ${ }^{20}$ I test H1a by estimating equation 2 without the Inc_Relv variables. A significant $\lambda_{1}$ coefficient (on the Pre-CF variable) indicates a significant difference in dissent rates across regimes.

I test $\mathrm{H} 2$ a by estimating equation 2 in full. By construction, the reference category for equation 2 is the $C F$ regime, so coefficient $\lambda_{2}$ represents the impact of standards increasing relevance on FASB Dissent in the $C F$ regime while the sum of coefficients $\left(\lambda_{2}+\lambda_{3}\right)$ represents the impact in the Pre-CF regime. If there is a change in FASB Dissent across regimes, a significant Inc_Relv coefficient in one regime (both regimes) demonstrates an association (strong association) between standards increasing relevance and the change in dissent.

\subsection{Hypotheses $1 b$ and $2 b$}

I test hypotheses $1 \mathrm{~b}$ and $2 \mathrm{~b}$ by estimating variations of equation 3 in a cross-sectional OLS regression, with each observation reflecting a standard.

$$
\begin{array}{r}
R_{t}=\alpha+\gamma_{1} * \text { Pre-CF }+\gamma_{2} * \text { Inc_Relv }_{t}+\gamma_{3} * \text { Inc_Relv }_{t} * \text { Pre }_{-} \text {CF } F_{t}+ \\
\gamma_{4} * \text { AvgTenure }_{t}+\gamma_{5} * \text { LagReturn }_{t}+\gamma_{6} * \text { ED_Frequency }_{t}+\varepsilon
\end{array}
$$

\footnotetext{
${ }^{19}$ At various points the FASB has either had a seven-person Board with a requirement for a 5-2 supermajority, a seven-person Board with a simple majority requirement, or a five-person Board with a simple majority requirement.

${ }^{20}$ To achieve an appropriate balance of combinations and total standards, I require a combination to have at least five associated standards. Therefore, combinations were identified by starting at SFAS 1 and changing combinations at every change in membership after the fifth standard attributed to each combination. This provides for seventeen combinations of FASB members across the 163 standards.

I exclude combination fixed effects, as they capture explanatory power related to systematic differences between each combination of FASB members, which is one of the elements the $C F$ split is designed to capture. A number of additional variables identified by prior literature as determinants of standard setting outcomes (e.g. political affiliation, professional background, etc.) are time-invariant personal characteristics and therefore also relate to differences between combinations of FASB members. As such, they are also excluded from my model.
} 
$R_{t}$ measures the diversity of FASB positions relative to sponsors' positions. Pre-CF is an indicator variable equal to one when the standard is issued in the Pre-CF regime. Inc_Relv identifies standards increasing accounting relevance. AvgTenure is the log of the average number of standards the members have voted on as of (and inclusive of) standard t. LagReturn is the lagged one-year return on the CRSP value-weighted index as of the date of the final ED to each standard. Because public demand for regulatory activity tends to peak following market failures (e.g., Becker 1983), regulators may have more inherent authority to produce industryunfriendly outputs in relatively poor economic periods than during strong periods. If this is the case, LagReturn should be positively related to $R_{t}$. ED_Frequency is the log of the number of EDs (that ultimately became standards) that were issued in the two prior years. To the extent constituent concerns of 'standards overload' (e.g., Hepp and McRae 1982) influence their position on an ED, the $E D \_$Frequency coefficient will be negative. I cluster standard errors by combination. I test $\mathrm{H} 1 \mathrm{~b}$ by estimating equation 3 without the Inc_Relv variables. A significant $\gamma_{1}$ coefficient (on the Pre-CF variable) indicates a significant difference in $R_{t}$ across regimes.

The format of $\mathrm{H} 1 \mathrm{~b}$ lends itself to further analysis within a difference-in-differences (Din-D) design. This design is desirable because it controls for permanent differences between the FASB and its sponsors as well as for inter-temporal changes that affect both groups. In order to execute this design, I first develop a measure of sponsor dissent similar to FASB dissent: I code positions less than (equal to) 0.5 as a dissent (one-half of a dissent). I then execute a D-in-D of total FASB and sponsor dissents relating to all matched votes in the Pre- $C F$ and the $C F$ regimes. The significance of the overall D-in-D provides a supplementary test of H1b.

I test $\mathrm{H} 2 \mathrm{~b}$ by estimating equation 3 in full. By construction, the reference category for equation 3 is $C F$, so coefficient $\gamma_{2}$ represents the impact of standards increasing relevance on 
Representativeness in the $C F$ regime while the sum of coefficients $\left(\gamma_{2}+\gamma_{3}\right)$ represents the impact in the Pre-CF regime. If there is a change in Representativeness across regimes, a significant Inc_Relv coefficient in one regime (both regimes) demonstrates an association (strong association) between standards increasing relevance and the change in Representativeness.

\subsection{Hypothesis 2b: $C F \_R e f s$ and Constituent Dissent}

While I cannot use $C F \_R e f s$ in equations (2) and (3) due to endogeneity concerns, I can use this variable to shed light on hypothesis $2 \mathrm{~b}$, as follows.

$$
\begin{aligned}
& \text { ConstDissent } \%_{t}=\alpha+\tau_{1} * \text { Pre-CF } F_{t}+\tau_{2} * \text { Inc_Relv } v_{t}+\tau_{3} * \text { Inc_Relv } * \text { Pre }-C F_{t}+ \\
& \tau_{4} * C F_{-} R e f s_{t}+\tau_{5} * C F_{-} R_{e f s_{t}}^{*} \text { Pre }-C F_{t}+\varepsilon
\end{aligned}
$$

ConstDissent\% is the percent of sponsors' dissents on each standard; I use a Tobit regression because it is left-censored at zero. Pre-CF is an indicator variable equal to one when the standard is issued in the Pre-CF regime. Inc_Relv identifies standards increasing accounting relevance. $C F \_$Refs identifies the frequency of authoritative references to the $\mathrm{CF}$. This test can demonstrate how standards associated with the CF differentially affect the diversity of sponsors' positions in both the Pre-CF and $C F$ regimes, providing partial evidence towards $\mathrm{H} 2 \mathrm{~b}$.

By construction, the reference category for equation 4 is $C F$, so coefficient $\tau_{2}\left[\tau_{4}\right]$ represents the impact of standards increasing relevance [how often standards cite the $\mathrm{CF}$ ] on ConstDissent\% in the $C F$ regime while the sum of coefficients $\left(\tau_{2}+\tau_{3}\right)\left[\tau_{4}+\tau_{5}\right]$ represents the impact in the Pre-CF regime. Because this test provides only partial evidence towards $\mathrm{H} 2 \mathrm{~b}, \mathrm{I}$ will consider the results from this test in conjunction with results generated from other tests.

\subsection{Hypothesis 3}

Hypothesis 3 compares the rate of 'inside' opposition on standards associated with the framework in the Pre-CF and $C F$ regimes. I test this by identifying whether there is a change in the rate of 'inside dissent' on fair value standards; see Figure 4. I focus on fair values because 
standards in recent years have called for an increased use of fair values, and because the FASB has linked fair value accounting to the CF (Johnson 2005).

At the end of each standard, dissenting FASB members provide an explanation for their vote. I hand-collect each of these dissenting explanations on fair value standards. With the support of a research assistant, I follow a coding process in which each explanation is first divided into distinct arguments, and then each argument is categorized. ${ }^{21}$ Two such categories are "Prefer lesser use of current costs or fair values" and "Prefer greater use of current costs or fair values." I test H3 by comparing the percentage of greater-use-of-fair-value dissents on fair value standards in the Pre-CF and $C F$ regimes.

As I focus on the diversity of positions taken by FASB members, when estimating equations (2) and (3) I include adjusted variables in which I convert 'inside' dissents to assents.

\section{RESULTS}

\subsection{Descriptive Statistics}

Detail on the definitions, construction, and availability of all variables is included within Appendix 1. Figure 5 presents temporal patterns of FASB dissent, constituent (i.e., sponsor) dissent, and standard type for the matched sample of FASB votes. It provides initial evidence of changes in the $C F$ regime: an increase in standards increasing accounting relevance coinciding with a decrease in FASB dissent and an increase in sponsor dissent.

Panels A, B, and C of Table 1 provide descriptive statistics for key variables - Panel A for the full sample, while Panel B (Panel C) separates the Pre-CF and CF regimes (Inc_Relv and

\footnotetext{
21 The coding process operated as follows. I read every dissenting argument (based upon a random order of standards) and coded/categorized each one. A research assistant (RA) who was not provided with the initial coding decisions then independently coded each argument. Where there was a disagreement between our coding decisions, the RA re-reviewed the argument and determined the final argument type. The RA is an accounting PhD student and licensed CPA who was not informed about the topic or objectives of this study.
} 
non-Inc_Relv standards). Panel B provides initial evidence that FASB dissent and

Representativeness decrease across regimes, and indicates that the preparer sponsors prefer Pre$C F$ standards to $C F$ ones, while the user sponsors have opposite preferences. Per Panel C, auditor and preparer sponsors oppose Inc_Relv standards (relative to non-Inc_Relv standards), whereas users and academics do not. Panel D provides the correlation matrix, and documents a strong positive relationship between the positions taken by auditors and preparers and by users and academics, but no significant relation between positions of any other constituent pairing.

Panel A of Table 2 provides data for the matched sample of votes. Consistent with the overall population, the matched sample shows a decrease in FASB dissent and increase in sponsor dissent in the $C F$ regime. I will discuss the overall D-in-D along with results for H1b.

Panel B of Table 2 provides CL submission frequencies to help identify systematic patterns to "missing" CLs that might confound $\mathrm{H} 1 \mathrm{~b}$ and $\mathrm{H} 2 \mathrm{~b}$. For auditors and academics, there is no association between changes in submission and changes in dissent. For preparers and users, lower submission rates are associated with greater dissent. If the latter groups' unobserved positions are more likely to be dissents, this may infer greater user (preparer) dissent in the Pre$C F(C F)$ regime. As such, the effect of these dissents would largely offset in the D-in-D.

\subsection{Results of Hypothesis Tests}

\subsubsection{Hypotheses $1 a$ and $2 a$}

Table 3 provides results from multivariate tests of hypotheses $1 \mathrm{a}$ and $1 \mathrm{~b}$. Columns (1), (2), and (3) use FASB Dissent, while columns (4), (5) and (6) use an adjusted FASB Dissent variable that converts 'inside' dissenting votes on fair value standards to assents. Columns (1) and (4) include only the Pre-CF indicator variable, while columns (2) and (5) include control 
variables. Pre-CF is positive and significant in all four columns, indicating a reduction in the diversity of individual FASB member positions; as such, I reject H1a.

Results from testing hypothesis $2 \mathrm{a}$ are in columns (3) and (6) of Table 3 . The data indicate a significantly positive association between Inc_Relv standards and FASB dissent in the Pre- $C F$ regime, and a significantly negative association in the $C F$ regime when adjusting for inside dissenting votes. As such, there is a strong association between standards that increase accounting relevance and the decline in FASB dissent across regimes, and I reject $\mathrm{H} 2 \mathrm{a}^{22}$

\subsubsection{Hypotheses $1 b$ and $2 b$}

Table 4 provides results from multivariate tests of hypotheses $1 \mathrm{~b}$ and $2 \mathrm{~b}$. Columns (1), (2), and (3) use $R_{t}$, while columns (4), (5), and (6) are run using an adjusted $R_{t}$ variable that converts 'inside' dissents on fair value standards to assents. Columns (1) and (4) include only Pre-CF, while columns (2) and (5) include control variables. Pre-CF is positive and significant in all four columns. The D-in-D result (Table 2, Panel A) further supports the finding that FASB positions during the $C F$ regime are less diverse than the positions of its sponsors. I reject $\mathrm{H} 1 \mathrm{~b}$.

Results from testing hypothesis $2 \mathrm{~b}$ are in columns (3) and (6) of Table 4. The data indicate a significantly negative association between $I n c_{-}$Relv and $R_{t}$ in the $C F$ regime, both before and after adjusting for inside dissenting votes. As such, there is an association between the decline in the diversity of FASB positions (relative to its sponsors) and standards that increase relevance, and I reject $\mathrm{H} 2 b .^{23}$

\footnotetext{
${ }^{22}$ As described in section 3.1, a significant coefficient in both regimes demonstrates a strong association. Because dissent decreased, this represents a positive (negative) coefficient for the Pre-CF $(C F)$ regime. The Pre-CF coefficient is positive and significant in both specifications. The $C F$ coefficient is significant when adjusting for inside dissents on fair value standards - which, by construction, are in the set of Inc_Relv standards. As such, the modified variable more precisely measures the positions taken by FASB members on these standards. This demonstrates a strong association: Inc_Relv standards are associated with a greater diversity of FASB positions during the Pre-CF regime as well as with a lower diversity during the $C F$ regime.

${ }^{23}$ As described in section 3.2, a significant coefficient in one regime demonstrates an association. Because $R_{t}$ decreased, this represents a positive (negative) coefficient for the Pre-CF $(C F)$ regime. As the $C F$ coefficient is
} 


\subsubsection{Hypothesis 2b: $C F \_R e f s$ and constituent dissent}

Table 5 provides results for equation (4). Column (1) confirms that constituent (i.e., sponsor) dissent was lower in the Pre-CF regime, while column (2) indicates that Inc_Relv standards did not significantly increase constituent dissent during the $C F$ regime (p-value $=0.12$ ). Column (3) indicates that the frequency of references to the CF in a standard is strongly associated with greater constituent dissent to that standard. Column (4) confirms that all significant results from columns (2) and (3) remain significant when all variables are included.

Two results are particularly notable. First, the Pseudo $\mathrm{R}^{2}$ increases from $1.7 \%$ in column (1) to $11.4 \%$ in column (3). Second, the coefficient on the Pre-CF variable is significantly negative in column (1), but is positive (though insignificant) in column (3). This indicates that variation in $C F \_R e f s$ accounts for all of the increase in sponsor dissent in the $C F$ regime.

The Pearson [Spearman] correlation between FASB Dissent and $C F \_$Refs is significantly positive in the $P r e-C F$ regime (p-value $=0.01$ [0.02]; untabulated) but insignificantly negative in the $C F$ regime (p-value $=0.82$ [0.85]; untabulated). As such, during the $C F$ regime, FASB dissent was unassociated with how frequently standards cited the framework. However, Table 5 demonstrates that references to the $\mathrm{CF}$ are highly associated with sponsor dissent. This result is difficult to interpret because the direction of causality is uncertain - that is, whether sponsors dissent to EDs that cite the CF, or whether the FASB cites the CF more frequently in response to sponsor dissent. In total, however, the evidence supports some sort of relationship between the $\mathrm{CF}$ and the decline in the diversity of FASB positions relative to their sponsors.

negative and significant, this demonstrates an association: Inc_Relv standards are associated with lower FASB representativeness during the $C F$ regime. While the Pre-CF coefficient is also negative, the impact in magnitude is much larger during the $C F$ regime, where there were many more Inc_Relv standards - an increase of more than $500 \%$ over the Pre-CF regime (per Table 1, Panel B). 


\subsubsection{Hypothesis 3}

Results for testing hypothesis 3 are in Panel A of Table 6. All standards on which I identify inside dissent in the $C F$ regime are included in Panel B. There are seven (thirty-two) fair value standards in the Pre-CF $(C F)$ regime, on which the dissent rate is $32.7 \%(8.3 \%)$. On fair value standards in the Pre-CF regime, two (three) of the sixteen dissenters argue for lesser (greater) use of fair values. In the $C F$ regime, three (eleven) of the eighteen total dissenters argue for lesser (greater) use of fair values. Notwithstanding the small populations, the increase is statistically significant (two-tailed p-value $=0.01$ ), and I reject $\mathrm{H} 3$.

On the twenty-two most recent fair value standards in my sample, encompassing 149 votes, there is only one FASB dissent that does not explicitly call for an even greater use of fair values. Over those same standards, I identify 42.5 constituent dissents on 117 matched votes. ${ }^{24}$ This data demonstrates a significant decline in the diversity of FASB positions in the $C F$ regime on the issue of fair value accounting.

\subsection{Differences Between Constituent Groups}

Descriptive statistics in Table 1 reveal an alignment between positions taken by academic and user sponsoring organizations, with the user sponsors (primarily the CFA Institute) demonstrating particularly strong support for the FASB in the $C F$ regime. I identify thirteen of the most unpopular standards in the $C F$ regime, and within this subsample the median $P O S_{j}$ value for each constituent group is 0.25 (auditor and preparer) and 0.75 (user and academic). ${ }^{25} \mathrm{I}$

\footnotetext{
${ }^{24}$ Some of the opposition embedded in constituent positions may also come from the 'inside.' Relative to the other constituent groups, financial statement users demonstrated the greatest support for the direction taken by the FASB in the $C F$ regime (Table 1, Panel B), and I note a total of four user dissents across the entire $C F$ regime (Table 2 , Panel B). As such, it is unlikely that many of these constituent dissents reflect requests for greater use of fair values.

${ }^{25}$ I identified the standards using the following criteria: standards in the $C F$ regime with either (i) four or more constituent dissents or (ii) with at least three matched votes and a constituent dissent percentage greater than $67 \%$. The thirteen standards are SFASs 94, 101, 113, 125, 130, 131, 142, 143, 146, 147, 150, 132R, and 141R.
} 
document user positions for twelve of these standards, and on only three standards do any other constituency have a higher $P O S_{j}$ value.

Descriptive statistics also reveal an overall alignment between auditor and preparer sponsors, as well as their opposition to standards increasing relevance. Further, per Panel B of Table 2, most of the increase in constituent dissent in the $C F$ regime is driven by preparer sponsors, followed by auditor sponsors. In total, this indicates that results in $\mathrm{H} 1 \mathrm{~b}$ and $\mathrm{H} 2 \mathrm{~b}$ are primarily driven by differences between FASB members with auditor and preparer backgrounds and the sponsoring organizations representing those constituent groups.

\subsection{Robustness Procedures}

\subsubsection{Robustness procedures: Sensitivity to different CF 'break' points}

Reviewing the data underlying Figure 2, the earliest plausible alternate 'break' point is after SFAS 67, which was the last to reference that the CF was incomplete, and which immediately preceded a small increase in references to the framework (see Figure 2 and $C F \_R e f s$ in Appendix 3). To demonstrate that my results are robust to alternate break points, I re-perform hypothesis tests for H1a, H1b, H2a, and H2b using SFAS 67, 75 and 83 to delineate regimes. ${ }^{26}$

The result for H1a is not significant for any of the earlier break points, as the decrease in FASB dissent in the reconfigured $C F$ regimes - without adjusting for inside dissenting votes - is no longer significant. However, results for all other hypotheses remain significant, for all earlier break points (though $\mathrm{H} 1 \mathrm{~b}$ is marginal for SFAS 67). In summary, the findings of a decline in the $C F$ regime in the diversity of FASB members' positions relative to their sponsors' positions, which is more pronounced on standards associated with the framework, continues to hold with $C F$ regime break points as early as SFAS 67 - when the FASB declared the CF incomplete.

\footnotetext{
${ }^{26}$ In general, I re-perform tests of $\mathrm{H} 1 \mathrm{a}$ and $\mathrm{H} 2 \mathrm{a}$ [H1b and $\left.\mathrm{H} 2 \mathrm{~b}\right]$ by re-estimating columns (2) and (6) of Table 3 [Table 4], respectively. Here, I also re-perform the D-in-D for H1b and re-estimate column (4) of Table 5 for H2b.
} 


\subsubsection{Robustness procedures: Alternate 'matching' process}

Because the weighting of each constituent group varies with changes in Board composition, results for $\mathrm{H} 1 \mathrm{~b}$ and $\mathrm{H} 2 \mathrm{~b}$ may be driven by temporal changes in FASB composition rather than by sponsors' preferences. To address this, I perform alternate tests in which I 'match' each FASB vote to the average position of all constituent groups submitting a related CL (i.e., the average $P O S_{j}$ for standard $t$ ). This increases the number of usable FASB votes and more closely aligns the vote sample with my current tests of H1a and H2a.

I first re-perform the $\mathrm{D}$-in-D, and note that the results remain significant under this alternate matching process $(\mathrm{D}$-in- $\mathrm{D}=-12.6 \% ; \mathrm{t}$-stat $=-4.60$; untabulated $)$. I then use this process to develop a modified version of $R_{t}$. I note that the observed decline in $R_{t}$ in the $C F$ regime is greater using the modified variable, in both economic magnitude and statistical significance (diff $=-0.129 ; \mathrm{t}$-stat $=-4.60$; untabulated). Further, I re-perform tests for $\mathrm{H} 1 \mathrm{~b}$ and $\mathrm{H} 2 \mathrm{~b}$ with this modified variable, and there are no instances in which a previously significant coefficient of interest is statistically insignificant.

\subsubsection{Robustness procedures: Changes to Exposure Drafts}

It is possible that significant changes are made from the ED on which I measure sponsors' positions to the standard on which I observe FASB voting. Such instances bias my results to the extent their frequency differs across regimes - for example, if the FASB responded to constituent dissatisfaction in the $C F$ regime by making more substantive changes to EDs without issuing a new ED. To address this possibility, I estimate equation 5 with a crosssectional regression using OLS with standard errors clustered by Combination.

$$
\begin{gathered}
\text { TimeLag }_{t}=\alpha+\zeta_{1} * \text { Pre-CF } F_{t}+\zeta_{2} * \text { ConstDissent } \%_{t}+ \\
\zeta_{3} * \text { ConstDissent } \%_{t}^{*} \text { Pre-CF } F_{t}+\varepsilon
\end{gathered}
$$


TimeLag is the log of the number of months between issuance of the (final) ED and the standard, which I use to proxy for the degree of change made to the ED after its release. Pre-CF is an indicator variable equal to one when the standard is issued in the Pre-CF regime.

ConstDissent\% is the percent of constituent dissents on each standard. I interpret a negative $\zeta_{3}$ coefficient as evidence of a shift in which the FASB made more changes to EDs in response to constituent dissatisfaction in the $C F$ regime. The estimated $\zeta_{3}$ coefficient is insignificant $\left(\zeta_{3}=-\right.$ 0.25 , two-tailed $\mathrm{p}$-value $=0.58$; untabulated), which is inconsistent with such a shift taking place.

\subsubsection{Robustness procedures: Miscellaneous}

Some standards are more important to the FASB's constituents than others. To demonstrate that my results are not driven by relatively unimportant standards, I re-perform hypothesis tests for $\mathrm{H} 1 \mathrm{a}, \mathrm{H} 1 \mathrm{~b}, \mathrm{H} 2 \mathrm{a}$, and $\mathrm{H} 2 \mathrm{~b}$ after excluding standards in the bottom quartile of the total number of CLs submitted to the final ED. For all hypotheses, there are no instances in which the coefficient(s) of interest is statistically insignificant after the removal of relatively unimportant standards.

It is also possible that my results are influenced by coding errors. Systematic coding errors are unlikely to influence my findings, as they are likely to offset or "cancel out" in my analyses. I test the sensitivity of my results to idiosyncratic coding error by performing jackknife procedures for tests of $\mathrm{H} 1 \mathrm{~b}$ and $\mathrm{H} 2 \mathrm{~b}$, in which the regressions are estimated by successively eliminating one observation. For both hypotheses, there are no instances in which the coefficient of interest is statistically insignificant after the elimination of an observation. ${ }^{27}$

\footnotetext{
${ }^{27}$ To facilitate the removal of individual observations, the jackknife estimations of the regressions in columns (2) and (6) of Table 4 are performed with robust but non-clustered standard errors.
} 


\section{DISCUSSION AND SUPPLEMENTARY ANALYSIS}

\subsection{Discussion}

\subsubsection{Inferential limitations}

In much of my analysis, I use an indicator variable to measure differences across regimes, in effect treating the $\mathrm{CF}$ as an exogenous parameter when it is clearly endogenous to my setting. As such, the results from $\mathrm{H} 1 \mathrm{a}$ and $\mathrm{H} 1 \mathrm{~b}$ are subject to the inferential limitation that I cannot distinguish the extent to which the results arise due to the framework itself or due to the forces and conditions that created the framework. It is also possible that the results from $\mathrm{H} 1 \mathrm{a}$ and $\mathrm{H} 1 \mathrm{~b}$ are spurious, driven by any number of unrelated factors with differential impact across regimes. For example: changes to the broader institutional structure, such as the composition of FAF Trustees (Miller 2002) or brought about by government oversight (e.g., the Sarbanes-Oxley Act); changes to the FASB's due process (see Note 11); or changes in FASB members' idiosyncratic motivations (e.g., career concerns). However, explanations of this type cannot reconcile the cross-sectional results in Tables 3, 4, 5, and 6, which support some sort of link to the CF.

Lastly, my results are subject to inferential limitations regarding the broader effects of conceptual frameworks on standard setting, as, in this matter, my study contributes only a single case. Further research is necessary to build our knowledge in this area.

\subsubsection{Pattern in the CF regime appears to be increasing over time}

As Baxter (1962)'s prediction is meant to explain long-term conditions, it is interesting to note that the trends in the $C F$ regime in Figure 5 appear to be increasing through time. I regress Representativeness on a Pre-CF time trend variable, a $C F$ time trend variable, and the Pre-CF indicator variable - with similar specifications as equation 3 - and discover that the decline in $R_{t}$ in the $C F$ regime is increasing in magnitude over time ( $\mathrm{p}$-value $=0.02$; untabulated). 
This trend is consistent with a specific form of institutional change. Once the FASB decides to move in a certain direction, for example to focus on decision usefulness, this decision can be reinforced absent interference from outside sources, because the cost of effort required to change paths acts as a barrier (Hathaway 2001), leading institutional self-reinforcement to drive "path dependence" (North 1990; Page 2006). ${ }^{28}$ Further research is necessary to identify whether institutional factors were a key driver for changes in the $C F$ regime, or perhaps whether those with institutional power employed the framework as a tool to justify preferred standards.

\subsection{Supplementary Analysis}

\subsubsection{Selection or socialization?}

As described in Note 10, the signatories of sponsors' CLs include ten future members of the FASB. These data can shed some light on whether FASB members in the $C F$ regime favored certain standards prior to their joining the Board (the "selection" hypothesis). I estimate equation 6 in an ordered logit regression, with standard errors clustered by sponsor.

$$
\begin{aligned}
P O S_{m} \_ \text {Ordinal }=\alpha+ & \delta_{1} * F A S B \_P r e-C F+\delta_{2} * F A S B \_C F+ \\
& \delta_{3} * P O S \text { others_Ordinal }+\sum \mu_{1} * \text { Org_Fixed_Effects } s_{m}+ \\
& \sum \mu_{2} * \text { Org_Fixed_Effects }{ }_{m} * \text { Inc_Relv }+\varepsilon
\end{aligned}
$$

$P O S_{m}$ Ordinal represents the position of sponsor $m$ on each CL, and is transformed from the original $P O S_{m}$ taking values $\{0.0,0.25,0.5,0.75,1.0\}$ to take integer values $\{1,2,3,4,5\}$. $F A S B \_P r e-C F\left(F A S B \_C F\right)$ is an indicator variable equal to one when one of the CL signatories

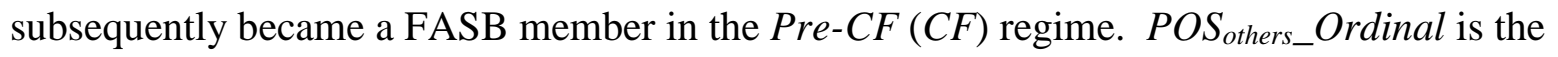
average of the ordinal CL positions taken by the other sponsors on the related standard. Inc_Relv identifies standards that increase accounting relevance. The interaction terms (with coefficients

\footnotetext{
${ }^{28}$ Miller et al. $(1994,25)$ note that one intended benefit of the CF was to eliminate "redundancy in discussions when the same basic issues are debated over and over again," indicating the FASB faced incentives to reinforce initial interpretations of the framework.
} 
$\left.\mu_{2}\right)$ control for cross-sectional variation in sponsor preferences on Inc_Relv standards, incremental to the overall sponsor preferences captured by the fixed effects $\left(\mu_{1}\right)$.

Results are included in Table 7. Column (1) shows that, for all standards, members selected in the $C F$ regime take significantly more favorable positions than Pre- $C F$ members. Column (2) shows that members selected in the $C F$ regime demonstrate an ex ante preference for Inc_Relv standards. While this result has marginal statistical significance (two-tailed pvalue $=0.07$, it is economically meaningful: ceteris paribus, the odds of a CL on an Inc_Relv standard being favorable are $292 \%$ higher when signed by a $C F$ regime FASB member. Column (3) shows that members selected in the $C F$ regime take more favorable positions on standards referencing the $\mathrm{CF}$, although the margin is statistically insignificant (two-tailed p-value $=0.16$ ).

Another possibility is that standard-setters' ideologies change during their tenure. For example, a socialization process may lead FASB members in the $C F$ regime to converge to the group norm over time (the "socialization" hypothesis). I estimate equations 2 and 3 separately for each regime, and interpret negative coefficients on the AvgTenure variable in the $C F$ regime as consistent with a socialization effect (i.e., more exposure to the FASB leads to reduced Board dissent and Representativeness), and positive coefficients as consistent with a "cold feet" effect (i.e., new FASB members are more likely to conform). ${ }^{29}$ For both equations, the AvgTenure coefficient is insignificant in the Pre-CF regime, but is positive and statistically significant in the $C F$ regime (p-values $=0.00$ and 0.03 ; untabulated), consistent with the "cold feet" hypothesis.

In sum, this preliminary evidence supports the 'cold feet' over the socialization hypothesis, and provides weak support of the selection hypothesis. However, further research is necessary to distinguish between, and build upon, the selection and socialization hypotheses.

\footnotetext{
${ }^{29}$ I estimate separate Pre-CF and $C F$ regressions, rather than estimating the entire sample as before, because the AvgTenure*Pre-CF interaction term introduces collinearity problems.
} 


\subsubsection{Are key standards promulgated more timely in the CF regime?}

It is possible the CF has helped the FASB promulgate key standards on a timelier basis in the $C F$ regime. To bring initial evidence towards this, I collect the date that each standard was initially added to the FASB's agenda, and I construct a variable, OverallLag, equal to the log of the number of months between the agenda date and the issuance of the standard. Detail into the collection of FASB agenda data is included in a supplemental internet appendix.

I regress OverallLag on the log of the number of comment letters relating to each standard (which I use to measure the relative importance of each standard), and I measure the Pre-CF/CF split as in prior equations. Indeed, the coefficient of interest in the $C F$ regime is 44\% smaller than for the Pre-CF regime. Across all standards, the average OverallLag is 819 days (that is, 2.2 years-to-complete); for a standard in the $75^{\text {th }}$ percentile of CLs received, the effect is 75 fewer days-to-complete ( 2.5 months) in the $C F$ regime.

While the difference appears economically significant, the coefficient is not statistically significant (two-tailed $\mathrm{p}$-value $=0.21$; untabulated). Further research is necessary to help determine whether key standards are promulgated on a more timely basis in the $C F$ regime. ${ }^{30}$

\section{CONCLUSION}

In some respects, this study raises more questions than it provides answers. If the conceptual framework has driven a significant long-term decline in ideological diversity within the FASB, then scholars might be interested in researching the causes and consequences of this shift. In Section 5, I bring preliminary evidence towards some of the many possible directions for further research. I present two additional directions here.

\footnotetext{
${ }^{30}$ Such research should also consider any effects of the FASB's formal attempts to increase its efficiency and responsiveness (e.g., McKenna 2003).
} 
- It would be useful to have an ex ante measure of FASB members' ideologies. This would allow for: (i) tests to specify how influential ideology is on members' votes; (ii) tests to confirm whether the Board's ideological diversity declined in the $C F$ regime; (iii) tests to identify how members' ideologies, including the interplay of members with varying ideologies, affect standard setting outcomes; and (iv) tests of the "selection" hypothesis (Section 5.2.1).

- Janis $(1982,244)$ documents that low ideological diversity can be a precursor to adverse group decision-making processes. ${ }^{31}$ Given the significance of this hypothetical consequence, more research into the antecedent conditions and groupthink symptoms would be useful.

The FASB arose from a high-stress period with dual goals of (i) promoting a diversity of views and backgrounds (AICPA 1972) and (ii) developing conceptually consistent standards (AICPA 1973). Both goals addressed perceived weaknesses of the FASB's predecessors, in order to establish a stable standard setting body and reduce external pressure on the profession. I propose that these goals may naturally be in conflict, such that a stable equilibrium arises only when one goal dominates the other. If so, then perhaps the profession might consider whether the institutionalization of standard setting has led to a narrowing of thought among standardsetters - and possibly even, as Baxter (1962) cautioned, within the profession at large.

\footnotetext{
31 These include an incomplete survey of alternatives; a failure to examine the risks of the preferred choice; a failure to reappraise initially rejected alternatives; and a selective bias in processing information.
} 


\section{REFERENCES}

AAA. 1971. The Role of the American Accounting Association in the Development of Accounting Principles. The Accounting Review 46 (3):609-616.

Agrawal, S. P. 1987. On the conceptual framework of accounting. Journal of Accounting Literature 6:165-178.

AICPA. 1972. Establishing Financial Accounting Standards: Report of the Study on Establishment of Accounting Principles. New York, NY: American Institute of Certified Public Accountants, Inc. 1973. Objectives of Financial Statements: Report of the Study Group on the Objectives of Financial Statements. New York, NY: American Institute of Certified Public Accountants, Inc.

Allen, A., and K. Ramanna. 2013. Towards an understanding of the role of standard setters in standard setting. Journal of Accounting and Economics 55 (1):66-90.

Ansolabehere, S., J. M. Snyder, and M. Tripathi. 2002. Are PAC Contributions and Lobbying Linked? New Evidence from the 1995 Lobby Disclosure Act. Business and Politics 4 (2):131-155.

APB. 1970. Statement of the Accounting Principles Board: Basic Concepts and Accounting Principles Underlying Financial Statements of Business Enterprises". New York, NY: The American Institute of Certified Public Accountants, Inc.

Baxter, W. T. 1962. Recommendations on Accounting Theory. In Studies in Accounting Theory, edited by W. T. Baxter and S. Davidson. Homewood, IL: Richard D. Irwin, Inc.

. 1981. Accounting Standards-Boon or Curse? Accounting and Business Research 12 (45):3-10.

Becker, G. S. 1983. A Theory of Competition Among Pressure Groups for Political Influence. The Quarterly Journal of Economics 98 (3):371-400.

Brown, L. D., and E. H. Feroz. 1992. Does the FASB Listen to Corporations? Journal of Business Finance \& Accounting 19 (5):715-731.

Buckmaster, D., E. Saniga, and S. Tadesse. 1994. Measuring the Lobbying Influence Using the Financial Accounting Standards Board Public Record. Journal of Economic \& Social Measurement 20 (4):331-356.

Chatov, R. 1975. Corporate Financial Reporting: Public or Private Control? New York, NY: The Free Press.

Dopuch, N., and S. Sunder. 1980. FASB's Statements on Objectives and Elements of Financial Accounting: A Review. The Accounting Review 55 (1):1-21.

Epstein, L., and J. Knight. 1998. The Choices Justices Make. Washington, DC: Congressional Quarterly Press.

FAF. 2008. The Financial Accounting Foundation Board of Trustees Approves Changes to Oversight, Structure and Operations of FAF, FASB and GASB http://www.fasb.org/faf/nr022608.pdf (last accessed 3/19/2015).

FASB. 1973. Seven Projects Underway as Board Tackles First Technical Agenda. The FASB Report June $18,1973$.

1976. Scope and Implications of the Conceptual Framework Project. Stamford, CT: FASB. 1981. Statement of Financial Accounting Standards No. 48: Revenue Recognition When Right of Return Exists. Norwalk, CT: FASB.

1984. Statement of Financial Accounting Concepts No. 5: Recognition and Measurement in Financial Statements of Business Enterprises. Norwalk, CT: FASB. 2008. EXPOSURE DRAFT Conceptual Framework for Financial Reporting: The Objective of Financial Reporting and Qualitative Characteristics and Constraints of Decision-Useful Financial Reporting Information. Norwalk, CT: FASB.

Gellein, O. S. 1986. Financial Reporting: The State of Standard Setting. Advances in Accounting 3:3-23. Georgiou, G. 2004. Corporate Lobbying on Accounting Standards: Methods, Timing and Perceived Effectiveness. Abacus 40 (2):219-237.

Gerboth, D. L. 1987. The Conceptual Framework: Not Definitions, But Professional Values. Accounting Horizons 1 (3):1-8. 
Gipper, B., B. J. Lombardi, and D. J. Skinner. 2013. The politics of accounting standard-setting: A review of empirical research. Australian Journal of Management 38 (3):523-551.

Gore, P. 1992. The FASB Conceptual Framework Project 1973-1985: An analysis. Manchester, UK: Manchester University Press.

Hansen, T. B. 2011. Lobbying of the IASB: An Empirical Investigation. Journal of International Accounting Research 10 (2):57-75.

Hathaway, O. A. 2001. Path Dependence in the Law: The Course and Pattern of Legal Change in a Common Law System. The Iowa Law Review 86 (2):101-165.

Healy, P. M., and J. M. Wahlen. 1999. A Review of the Earnings Management Literature and Its Implications for Standard Setting. Accounting Horizons 13 (4):365-383.

Hepp, G. W., and T. W. McRae. 1982. Accounting standards overload: relief is needed. Journal of Accountancy 153 (5):52-62.

Honderich, T. 2005. The Oxford Companion to Philosophy. Second ed. Oxford, England: Oxford University Press.

Horngren, C. T. 1973. The marketing of accounting standards. Journal of Accountancy 136:61-66.

Janis, I. L. 1982. Groupthink: Psychological Studies of Policy Decisions and Fiascoes. Second Edition, Revised ed. Boston, MA: Houghton Mifflin.

Jiang, J. X., I. Y. Wang, and D. Wangerin. 2017. How Does the FASB Make Decisions? A Descriptive Study of Agenda-Setting and the Role of Individual Board Members. Accounting, Organizations and Society (Forthcoming).

Johnson, L. T. 2004. Understanding the Conceptual Framework. The FASB Report December 28, 2004. 2005. Relevance and Reliability. The FASB Report February 28, 2005.

Kothari, S. P., K. Ramanna, and D. J. Skinner. 2010. Implications for GAAP from an analysis of positive research in accounting. Journal of Accounting and Economics 50 (2-3):246-286.

Martin, A. D., and K. M. Quinn. 2002. Dynamic Ideal Point Estimation via Markov Chain Monte Carlo for the U.S. Supreme Court, 1953-1999. Political Analysis 10 (2):134-153.

McKenna, T. L. 2003. Improving the Effectiveness of the FASB's Process. The FASB Report August 29, 2003.

McLeay, S., D. Ordelheide, and S. Young. 2000. Constituent lobbying and its impact on the development of financial reporting regulations: evidence from Germany. Accounting, Organizations and Society 25 (1):79-98.

Miller, P. B. W. 2002. Viewing the 1996 FAF Restructuring as Policy Making without a Formal Due Process. Accounting Horizons 16 (3):199-214.

Miller, P. B. W., R. J. Redding, and P. R. Bahnson. 1994. The FASB: The People, The Process, and The Politics. Third Edition ed. Burr Ridge, IL: Irwin.

Moody, S. M., and D. L. Flesher. 1986. Analysis of FASB Voting Patterns: Statement Nos. 1-86. Journal of Accounting, Auditing \& Finance 1 (4):319-330.

Moonitz, M. 1974. Studies in Accounting Research \#8: Obtaining Agreement on Standards in the Accounting Profession. Sarasota, FL: American Accounting Association.

Newman, D. P. 1981a. Coalition Formation in the APB and the FASB: Some Evidence on the Size Principle. The Accounting Review 56 (4):897-909. 1981b. An Investigation of the Distribution of Power in the APB and FASB. Journal of Accounting Research 19 (1):247-262.

North, D. C. 1990. Institutions, institutional change and economic performance. New York, NY: Cambridge University Press.

Page, S. E. 2006. Path dependence. Quarterly Journal of Political Science 1 (1):87-115.

Puro, M. 1984. Audit Firm Lobbying before the Financial Accounting Standards Board: An Empirical Study. Journal of Accounting Research 22 (2):624-646.

Ramanna, K. 2008. The implications of unverifiable fair-value accounting: Evidence from the political economy of goodwill accounting. Journal of Accounting and Economics 45 (2-3):253-281. 
2013. Why "Fair Value" is the Rule: How a Controversial Accounting Approach Gained Support. Harvard Business Review 91 (3):99-101.

2015. Political Standards: Corporate interest, ideology, and leadership in the shaping of accounting rules for the market economy. Chicago, IL: The University of Chicago Press.

Rohde, D. W. 1972. Policy Goals and Opinion Coalitions in the Supreme Court. In Probability Models of Collective Decision Making, edited by R. G. Niemi and H. F. Weisberg. Columbus, OH: Charles E. Merrill Publishing Company.

Segal, J. A., and A. D. Cover. 1989. Ideological Values and the Votes of U.S. Supreme Court Justices. American Political Science Review 83 (2):557-565.

Segal, J. A., and H. J. Spaeth. 2002. The Supreme Court and the attitudinal model revisited. Cambridge, United Kingdom: Cambridge University Press.

Selto, F. H., and H. D. Grove. 1983. The Predictive Power of Voting Power Indices: FASB Voting on Statements of Financial Accounting Standards Nos. 45-69. Journal of Accounting Research 21 (2):619-622.

Solomons, D. 1986. The FASB'S Conceptual Framework: An Evaluation. Journal of Accountancy 161 (6):114-124.

Storey, R. K., and S. Storey. 1998. The Framework of Financial Accounting Concepts and Standards. Norwalk, CT: Financial Accounting Standards Board.

Sunder, S. 2010. Adverse effects of uniform written reporting standards on accounting practice, education, and research. Journal of Accounting and Public Policy 29 (2):99-114.

Van Riper, R. 1987. How Accounting Standards Are Set. Journal of Accountancy 163 (April 1987):130136.

Young, J. J. 2006. Making up users. Accounting, Organizations and Society 31 (6):579-600.

Zeff, S. A. 1971. Forging Accounting Principles in Five Countries: A History and Analysis of Trends. Champaign, IL: Stipes Publishing Company. 1978. The Rise of "Economic Consequences". Journal of Accountancy 146 (6):56-63. 1999. The Evolution of the Conceptual Framework for Business Enterprises in the United States. Accounting Historians Journal 26 (2):89-131. 2003. How the U.S. Accounting Profession Got Where It Is Today: Part II. Accounting Horizons 17 (4):267-281. 
APPENDIX 1. Variable detail: Definitions, construction, and availability

\begin{tabular}{|c|c|c|}
\hline $\begin{array}{l}\text { Variable Name } \\
\text { (Short Name) }\end{array}$ & $\begin{array}{l}\text { Variable } \\
\text { Type }\end{array}$ & Definition, Construction, and Availability \\
\hline $\begin{array}{l}\text { Constituent position } \\
\left(P O S_{j, t}\right)\end{array}$ & Discrete & $\begin{array}{l}\text { I measure the position of constituent group } j \text { on standard } t \text { as the average position taken by the group's sponsoring } \\
\text { organizations in comment letters to the final Exposure Draft related to the standard. I identify CLs submitted by sponsors } \\
\text { to the final ED relating to each standard, and match FASB votes on each standard to the position taken by that member's } \\
\text { sponsor(s). Positions taken by sponsors in CLs are classified into five categories: strongly oppose }\left(P O S_{m}=0\right) \text {, lean } \\
\text { oppose }(0.25) \text {, neither support nor oppose }(0.5) \text {, lean support }(0.75) \text {, and strongly support }\left(P O S_{m}=1\right) \text {. The sponsors are } \\
\text { identified in Figure } 1 \text {. I drop the Government constituency because their organizations (GFOA and NASACT) } \\
\text { submitted CLs on only two standards. These data are hand-coded for SFAS } 1 \text { through SFAS } 160 \text { (inclusive of revisions } \\
\text { SFAS 123R, 132R, and 141R). I identify a total of } 423 \text { constituent positions across those } 163 \text { standards. Refer to the } \\
\text { supplementary internet appendix for a description of the coding process. }\end{array}$ \\
\hline $\begin{array}{l}\text { FASB member position } \\
\left(P O S_{i, t}\right)\end{array}$ & Binary & $\begin{array}{l}\text { I measure the position of FASB member } i \text { on standard } t \text { by their vote: assent }\left(P O S_{i, t}=1\right) \text { or dissent }\left(P O S_{i, t}=0\right) \text {. Voting } \\
\text { data are hand-collected SFAS } 1 \text { through SFAS } 160 \text { (inclusive of revisions: SFAS } 123 \mathrm{R}, 132 \mathrm{R} \text {, and } 141 \mathrm{R}) \text {. }\end{array}$ \\
\hline $\begin{array}{l}\text { Number of matched } \\
\text { FASB votes }\left(n_{i, t}\right)\end{array}$ & Count & $\begin{array}{l}\text { The variable } n_{i, t} \text { measures the total number of matched FASB votes } i \text { on standard } t \text {. I am unable to 'match' a FASB vote } \\
\text { if the related sponsor(s) does not submit a comment letter on a standard. I match a total of } 762 \text { votes out of a possible } \\
1,011 \text { FASB votes (this total excludes votes by FASB members from the Government constituency). }\end{array}$ \\
\hline $\begin{array}{l}\text { Representativeness } \\
\left(R_{t}\right)\end{array}$ & Continuous & $\begin{array}{l}\text { This variable measures the diversity of FASB positions on standard } t \text { relative to sponsors' positions; see equation } 1 \\
\text { The metric is structured such that 'perfect' representativeness leads to a score of } 1.0 \text {. For each standard I require a } \\
\text { minimum of two FASB votes matched to sponsors' positions. I identify } 152 R_{t} \text { values out of the } 163 \text { standards from } \\
\text { SFAS } 1 \text { through SFAS } 160 \text { (inclusive of revisions). Refer to Appendix } 3 \text {, where I provide all } R_{t} \text { values. }\end{array}$ \\
\hline $\begin{array}{l}\text { Constituent dissent } \\
\text { (Constituent Dissent) }\end{array}$ & Discrete & $\begin{array}{l}\text { This variable transforms the constituent position variable }\left(P O S_{j, t}\right) \text { for each of the } 163 \text { standards from SFAS } 1 \text { through } \\
\text { SFAS } 160 \text { (inclusive of revisions), in order to allow a comparison to dissents made by FASB members. Constituent } \\
\text { positions less than } 0.5 \text { are coded a dissent, while positions equal to } 0.5 \text { are coded as one-half of a dissent. }\end{array}$ \\
\hline $\begin{array}{l}\text { Constituent dissent \% } \\
(\text { ConstDissent } \% t)\end{array}$ & Continuous & $\begin{array}{l}\text { This variable measures constituent dissent percentage on standard } t \text { (total constituent dissents } \div \text { total matched votes) } \\
\text { and is populated for } 159 \text { of the } 163 \text { standards from SFAS } 1 \text { through SFAS } 160 \text { (inclusive of revisions). }\end{array}$ \\
\hline $\begin{array}{l}\text { FASB dissent } \\
\text { percentage } \\
(\text { FASB Dissent })\end{array}$ & Continuous & $\begin{array}{l}\text { This variable is measured as the dissent percentage on FASB votes (total dissents } \div \text { total votes) for each of the } 163 \\
\text { standards from SFAS } 1 \text { through SFAS } 160 \text { (inclusive of revisions). This variable is calculated using the full population } \\
\text { of FASB votes, not only those matched to sponsors' positions. }\end{array}$ \\
\hline $\begin{array}{l}\text { Increase relevance } \\
(\text { Inc_Relv })\end{array}$ & Binary & $\begin{array}{l}\text { This variable identifies standards that increase perceived accounting relevance. It equals one if either of the two Allen } \\
\text { and Ramanna (2013) relevance metrics (inc_relv and Manual_inc_relv) is greater than zero. It is populated for } 160 \text { out } \\
\text { of the } 163 \text { standards from SFASs } 1 \text { through } 160 \text { (inclusive of revisions) - all except SFAS 38, 103, and 141R. }\end{array}$ \\
\hline $\begin{array}{l}\text { CF References } \\
\left(C F \_R e f s_{t}\right)\end{array}$ & Continuous & $\begin{array}{l}\text { This variable measures the frequency of authoritative references to the CF on standard } t \text {. It is measured as the log of [1 } \\
+ \text { (the number of authoritative references to the CF)] and is populated for each of the } 163 \text { standards from SFAS } 1 \text { through } \\
\text { SFAS } 160 \text { (inclusive of revisions). Refer to Appendix 3, where I provide all CF_Refs } s_{t} \text { values. }\end{array}$ \\
\hline $\begin{array}{l}\text { Average tenure } \\
(\text { AvgTenure })\end{array}$ & Continuous & $\begin{array}{l}\text { This variable identifies the average tenure of FASB members, and is measured as the log of the average number of } \\
\text { standards the members have voted on as of (and inclusive of) standard } t \text {. It is populated for each of the } 163 \mathrm{standards} \\
\text { from SFAS } 1 \text { through SFAS } 160 \text { (inclusive of revisions). }\end{array}$ \\
\hline
\end{tabular}




\begin{tabular}{|c|c|c|}
\hline $\begin{array}{l}\text { One-year lagged } \\
\text { market returns } \\
\left(\text { LagReturn }_{t}\right)\end{array}$ & Continuous & $\begin{array}{l}\text { This variable provides the lagged one-year market return as of the date of the final ED to each standard. It is calculated } \\
\text { from the daily Value-Weighted Return (including dividends) (Variable Name: VWRETD) from the CRSP Stock Market } \\
\text { Indexes file, and is populated for each of the } 163 \text { SFASs from } 1 \text { through } 160 \text { (inclusive of revisions). }\end{array}$ \\
\hline $\begin{array}{l}\text { Number of recent } \\
\text { FASB standards } \\
(\text { ED_Frequency })\end{array}$ & Continuous & $\begin{array}{l}\text { This variable is measured as the log of the number of Exposure Drafts (that ultimately became standards) that were } \\
\text { issued by the FASB in the two years prior to the date of the final ED to each standard. It is populated for each of the } \\
163 \text { standards from SFASs } 1 \text { through } 160 \text { (inclusive of revisions). }\end{array}$ \\
\hline $\begin{array}{l}\text { Standards issued in the } \\
\text { Pre-CF regime } \\
\left(\text { Pre }-C F_{t}\right)\end{array}$ & Binary & $\begin{array}{l}\text { This indicator variable identifies standards issued in the Pre-CF regime, and is equal to one for SFAS } 1 \text { through SFAS } \\
\text { 91. When Pre-CF is included as a stand-alone independent variable in a regression, the reference category in the } \\
\text { regression is } C F \text {, an excluded indicator variable equal to one for SFAS } 91 \text { through } 160 \text { (inclusive of revisions). }\end{array}$ \\
\hline $\begin{array}{l}\text { Standards issued } \\
\text { under a supermajority } \\
\text { vote (Supermajority })\end{array}$ & Binary & $\begin{array}{l}\text { This indicator variable is equal to one for the following standards which were issued under a required supermajority } \\
\text { vote: SFAS } 1 \text { through SFAS } 15 \text { and SFAS } 107 \text { through SFAS 144, and is populated for each of the } 163 \text { SFASs from } 1 \\
\text { through } 160 \text { (inclusive of revisions). }\end{array}$ \\
\hline $\begin{array}{l}\text { Sponsoring } \\
\text { organization position } \\
\left(P O S_{m \_} \text {Ordinal }\right)\end{array}$ & Discrete & $\begin{array}{l}\text { This variable represents the position of sponsoring organization } m \text { on each comment letter. Because it is used as a } \\
\text { dependent variable, I monotonically transform } P O S_{m} \text { which took values }\{0.0,0.25,0.5,0.75,1.0\} \text { such that the variable } \\
P O S_{m} \text { Ordinal takes integer values }\{1,2,3,4,5\} \text {. These data are hand-coded and are collected from comment letters } \\
\text { to the final ED for SFAS } 1 \text { through SFAS } 160 \text { (inclusive of revisions). I identify a total of } 528 \text { sponsoring organization } \\
\text { positions across those } 163 \text { standards. Refer to Appendix 2, where I provide all } P O S_{m} \text { values. }\end{array}$ \\
\hline $\begin{array}{l}\text { Pre-CF FASB member } \\
\left(F A S B \_P r e-C F\right)\end{array}$ & Binary & $\begin{array}{l}\text { This is an indicator variable equal to one when one of the signatories on a sponsor's CL was later selected to the FASB } \\
\text { in the Pre- } C F \text { regime. These data are hand-collected from CLs to the final ED for SFAS } 1 \text { through SFAS } 160 \text { (inclusive } \\
\text { of revisions). I identify a total of } 22 \text { such CLs. }\end{array}$ \\
\hline $\begin{array}{l}\text { CF FASB member } \\
\left(F A S B \_C F\right)\end{array}$ & Binary & $\begin{array}{l}\text { This is an indicator variable equal to one when one of the signatories on a sponsor's CL was later selected to the FASB } \\
\text { in the } C F \text { regime. These data are hand-collected from CLs to the final ED for SFAS } 1 \text { through SFAS } 160 \text { (inclusive of } \\
\text { revisions). I identify a total of } 37 \text { such CLs. }\end{array}$ \\
\hline 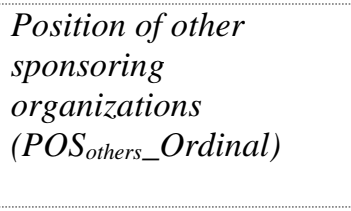 & Continuous & $\begin{array}{l}\text { This is the average of the ordinal comment letter positions taken by the other sponsors on the related standard. These } \\
\text { data are hand-collected from CLs to the final ED for SFAS } 1 \text { through SFAS } 160 \text { (inclusive of revisions). I drop all } \\
\text { comment letters where the related standard has fewer than two matched sponsoring organization positions; as such, this } \\
\text { will be the average position of one to four other organizations. Because of this requirement, I lose eight observations } \\
\text { (out of } 528 \text { sponsor positions) where only one sponsor submitted a CL on a standard. }\end{array}$ \\
\hline $\begin{array}{l}\text { Length of time between } \\
\text { issuance of the final } \\
\text { ED and the standard } \\
(\text { Time Lagt })\end{array}$ & Continuous & $\begin{array}{l}\text { This variable measures the length of time between the release of the final Exposure Draft related to standard } t \text { and the } \\
\text { standard itself, and is calculated as the log of the number of months between release of the ED and the standard. The } \\
\text { number of months is a continuous variable calculated as [(Date of standard - Date of ED)/30]. This variable is populated } \\
\text { for each of the } 163 \text { standards from SFASs } 1 \text { through } 160 \text { (inclusive of revisions). }\end{array}$ \\
\hline $\begin{array}{l}\text { Length of time between } \\
\text { the agenda date and } \\
\text { the standard issuance } \\
\text { (OverallLag })_{t}\end{array}$ & Continuous & $\begin{array}{l}\text { This variable measures the length of time between the date the project related to standard } t \text { was added to the agenda and } \\
\text { the release of standard } t \text {, and is calculated as the log of the number of months between the agenda date and the release } \\
\text { of the standard. The number of months is a continuous variable calculated as [(Date of standard - Agenda Date)/30]. } \\
\text { This variable is populated for each of the } 163 \text { standards from SFASs } 1 \text { through } 160 \text { (inclusive of revisions). }\end{array}$ \\
\hline
\end{tabular}


APPENDIX 2. Position of sponsoring organizations in comment letters, SFAS 1 - SFAS 160

\begin{tabular}{|c|c|c|c|c|c|c|c|c|c|c|c|}
\hline$\overline{S F A S}$ & Sponsor & $P_{O S S_{m}}$ & SFAS & Sponsor & $P O S_{m}$ & SFAS & Sponsor & $\mathrm{POS}_{m}$ & SFAS & Sponsor & $P O S_{m}$ \\
\hline 1 & AICPA & 0.75 & 13 & FEI & 0.5 & 26 & IMA & 1 & 41 & CFA Inst & 0.25 \\
\hline 1 & FEI & 0.75 & 13 & IMA & 1 & 27 & AICPA & 0.5 & 42 & AICPA & 0.75 \\
\hline 1 & IMA & 1 & 13 & CFA Inst & 1 & 27 & FEI & 1 & 42 & FEI & 0 \\
\hline 1 & CFA Inst & 1 & 13 & AAA & 1 & 27 & IMA & 1 & 42 & IMA & 0.5 \\
\hline 2 & AICPA & 0.75 & 14 & AICPA & 0.75 & 28 & AICPA & 0.75 & 43 & AICPA & 0.75 \\
\hline 2 & FEI & 1 & 14 & FEI & 0.5 & 28 & FEI & 0.75 & 43 & FEI & 0.5 \\
\hline 2 & IMA & 0.75 & 14 & IMA & 0.75 & 28 & IMA & 1 & 43 & IMA & 0.5 \\
\hline 2 & CFA Inst & 1 & 14 & CFA Inst & 0.75 & 29 & AICPA & 0.25 & 44 & AICPA & 1 \\
\hline 2 & AAA & 0.75 & 14 & AAA & 1 & 29 & FEI & 0 & 44 & IMA & 0.75 \\
\hline 3 & AICPA & 0.75 & 15 & AICPA & 0.5 & 29 & IMA & 1 & 45 & IMA & 1 \\
\hline 3 & FEI & 1 & 15 & FEI & 1 & 30 & AICPA & 1 & 47 & AICPA & 0.5 \\
\hline 3 & IMA & 1 & 15 & IMA & 0.75 & 30 & FEI & 1 & 47 & FEI & 0 \\
\hline 3 & CFA Inst & 1 & 15 & CFA Inst & 0.5 & 31 & AICPA & 0.75 & 47 & IMA & 1 \\
\hline 3 & AAA & 1 & 16 & AICPA & 1 & 31 & IMA & 1 & 48 & FEI & 1 \\
\hline 4 & AICPA & 0.75 & 16 & FEI & 1 & 32 & AICPA & 0.75 & 48 & IMA & 1 \\
\hline 4 & FEI & 0 & 16 & IMA & 1 & 32 & FEI & 1 & 49 & FEI & 1 \\
\hline 4 & IMA & 1 & 16 & CFA Inst & 1 & 32 & IMA & 1 & 49 & IMA & 1 \\
\hline 4 & CFA Inst & 0.75 & 17 & AICPA & 0.5 & 33 & AICPA & 0.75 & 50 & AICPA & 1 \\
\hline 5 & AICPA & 0.75 & 17 & IMA & 1 & 33 & FEI & 0.5 & 50 & IMA & 1 \\
\hline 5 & FEI & 0.5 & 18 & AICPA & 1 & 33 & IMA & 0.75 & 50 & AAA & 1 \\
\hline 5 & IMA & 0.75 & 18 & FEI & 1 & 33 & CFA Inst & 0 & 51 & AICPA & 0.75 \\
\hline 5 & CFA Inst & 1 & 18 & IMA & 1 & 33 & AAA & 0.75 & 51 & IMA & 1 \\
\hline 5 & AAA & 1 & 18 & CFA Inst & 0 & 34 & FEI & 0.5 & 51 & AAA & 1 \\
\hline 6 & AICPA & 0.75 & 19 & AICPA & 0.5 & 34 & IMA & 0.25 & 52 & AICPA & 0.75 \\
\hline 6 & FEI & 1 & 19 & CFA Inst & 1 & 34 & CFA Inst & 0.25 & 52 & FEI & 0.5 \\
\hline 6 & IMA & 1 & 20 & AICPA & 0.5 & 35 & AICPA & 0.75 & 52 & IMA & 0.25 \\
\hline 6 & CFA Inst & 1 & 20 & FEI & 1 & 35 & FEI & 0.5 & 53 & AICPA & 0.25 \\
\hline 6 & AAA & 1 & 20 & IMA & 1 & 35 & IMA & 0.75 & 53 & IMA & 1 \\
\hline 7 & AICPA & 0.75 & 21 & AICPA & 1 & 35 & CFA Inst & 0.5 & 53 & AAA & 1 \\
\hline 7 & FEI & 1 & 21 & FEI & 1 & 36 & AICPA & 0.75 & 54 & AICPA & 1 \\
\hline 7 & CFA Inst & 1 & 21 & IMA & 1 & 36 & FEI & 0 & 54 & FEI & 0 \\
\hline 8 & AICPA & 0.75 & 21 & CFA Inst & 0.25 & 36 & IMA & 0 & 55 & AICPA & 1 \\
\hline 8 & FEI & 0.5 & 22 & AICPA & 0.75 & 36 & CFA Inst & 0.75 & 55 & FEI & 1 \\
\hline 8 & IMA & 0 & 22 & FEI & 1 & 37 & AICPA & 1 & 55 & IMA & 1 \\
\hline 8 & CFA Inst & 0.75 & 22 & IMA & 0.5 & 38 & AICPA & 0.75 & 56 & FEI & 1 \\
\hline 9 & AICPA & 0.75 & 23 & AICPA & 0.75 & 38 & FEI & 1 & 56 & IMA & 1 \\
\hline 9 & FEI & 1 & 23 & FEI & 1 & 38 & IMA & 1 & 57 & AICPA & 0.75 \\
\hline 9 & CFA Inst & 1 & 23 & IMA & 1 & 39 & AICPA & 0 & 57 & FEI & 1 \\
\hline 10 & AICPA & 1 & 24 & AICPA & 1 & 39 & FEI & 0.25 & 57 & IMA & 1 \\
\hline 11 & AICPA & 0.75 & 24 & FEI & 1 & 39 & IMA & 0 & 58 & AICPA & 0.25 \\
\hline 11 & FEI & 1 & 24 & IMA & 1 & 39 & CFA Inst & 0.25 & 58 & FEI & 0.75 \\
\hline 11 & CFA Inst & 0.75 & 25 & AICPA & 1 & 40 & FEI & 0.25 & 58 & IMA & 1 \\
\hline 12 & AICPA & 0.75 & 25 & FEI & 1 & 40 & IMA & 0 & 59 & AICPA & 1 \\
\hline 12 & FEI & 0.25 & 25 & IMA & 1 & 40 & CFA Inst & 0.25 & 59 & IMA & 1 \\
\hline 12 & CFA Inst & 0.75 & 25 & CFA Inst & 0 & 41 & AICPA & 0 & 59 & AAA & 1 \\
\hline 12 & AAA & 0.75 & 26 & AICPA & 1 & 41 & FEI & 0.25 & 60 & AICPA & 0.5 \\
\hline 13 & AICPA & 0.75 & 26 & FEI & 1 & 41 & IMA & 0 & 60 & IMA & 1 \\
\hline
\end{tabular}




\begin{tabular}{|c|c|c|c|c|c|c|c|c|c|c|c|}
\hline$\overline{S F A S}$ & Sponsor & $\mathrm{POS}_{m}$ & SFAS & Sponsor & $\mathrm{POS}_{m}$ & SFAS & Sponsor & $\mathrm{POS}_{m}$ & SFAS & Sponsor & $\mathrm{POS}_{m}$ \\
\hline 61 & AICPA & 0.75 & 78 & IMA & 0 & 93 & IMA & 0.5 & 106 & AAA & 0.75 \\
\hline 61 & IMA & 1 & 79 & AICPA & 1 & 93 & AAA & 0.5 & 107 & AICPA & 0.75 \\
\hline 62 & AICPA & 0.75 & 79 & IMA & 1 & 94 & AICPA & 0.25 & 107 & FEI & 0.25 \\
\hline 62 & FEI & 0 & 80 & AICPA & 0.5 & 94 & FEI & 0.5 & 107 & IMA & 0.5 \\
\hline 62 & IMA & 1 & 80 & FEI & 0.75 & 94 & IMA & 0.5 & 107 & CFA Inst & 0.5 \\
\hline 62 & AAA & 0.25 & 80 & IMA & 1 & 94 & CFA Inst & 0.75 & 107 & AAA & 0.75 \\
\hline 63 & AICPA & 0.75 & 81 & AICPA & 0.25 & 94 & AAA & 0.75 & 108 & FEI & 1 \\
\hline 63 & IMA & 1 & 81 & FEI & 1 & 95 & AICPA & 0.75 & 108 & IMA & 1 \\
\hline 63 & AAA & 1 & 81 & IMA & 0.75 & 95 & FEI & 0.75 & 109 & AICPA & 0.75 \\
\hline 64 & AICPA & 1 & 81 & CFA Inst & 1 & 95 & IMA & 1 & 109 & FEI & 0.75 \\
\hline 64 & FEI & 0.75 & 82 & AICPA & 1 & 95 & CFA Inst & 0.75 & 109 & IMA & 0.75 \\
\hline 64 & IMA & 0.75 & 82 & FEI & 1 & 95 & AAA & 0.75 & 109 & CFA Inst & 0.75 \\
\hline 65 & AICPA & 0.75 & 82 & IMA & 1 & 96 & AICPA & 0.5 & 110 & AICPA & 1 \\
\hline 65 & IMA & 1 & 83 & AICPA & 1 & 96 & FEI & 0.25 & 110 & FEI & 1 \\
\hline 66 & AICPA & 0.75 & 83 & FEI & 1 & 96 & IMA & 0.5 & 110 & IMA & 1 \\
\hline 66 & IMA & 1 & 83 & IMA & 1 & 96 & AAA & 1 & 110 & CFA Inst & 0.5 \\
\hline 67 & AICPA & 0.75 & 84 & AICPA & 0.75 & 97 & AICPA & 0.5 & 111 & AICPA & 1 \\
\hline 67 & IMA & 1 & 84 & FEI & 0.75 & 98 & AICPA & 0.75 & 111 & FEI & 1 \\
\hline 68 & AICPA & 1 & 84 & IMA & 1 & 98 & FEI & 0.75 & 111 & IMA & 1 \\
\hline 68 & FEI & 0.75 & 85 & AICPA & 1 & 98 & IMA & 1 & 111 & CFA Inst & 1 \\
\hline 68 & IMA & 0 & 85 & FEI & 1 & 98 & AAA & 1 & 112 & AICPA & 0.75 \\
\hline 69 & AICPA & 0.75 & 85 & IMA & 1 & 99 & AICPA & 0.5 & 112 & FEI & 1 \\
\hline 69 & FEI & 0.5 & 86 & AICPA & 0.75 & 99 & FEI & 1 & 112 & IMA & 1 \\
\hline 69 & IMA & 0.25 & 86 & FEI & 1 & 99 & IMA & 1 & 112 & CFA Inst & 1 \\
\hline 70 & AICPA & 0.75 & 86 & IMA & 0.75 & 99 & AAA & 0 & 113 & AICPA & 0 \\
\hline 70 & FEI & 0.75 & 86 & CFA Inst & 0 & 100 & AICPA & 1 & 113 & FEI & 0.5 \\
\hline 70 & IMA & 1 & 87 & AICPA & 0.5 & 100 & FEI & 1 & 113 & CFA Inst & 1 \\
\hline 70 & AAA & 0.25 & 87 & FEI & 0 & 100 & IMA & 1 & 114 & AICPA & 0.75 \\
\hline 71 & AICPA & 0.75 & 87 & IMA & 0.25 & 100 & CFA Inst & 1 & 114 & FEI & 0.5 \\
\hline 71 & IMA & 1 & 87 & CFA Inst & 0.75 & 101 & AICPA & 0.25 & 114 & IMA & 0.5 \\
\hline 72 & AICPA & 0.75 & 87 & AAA & 0.75 & 101 & IMA & 0 & 114 & CFA Inst & 0.75 \\
\hline 72 & FEI & 0 & 88 & AICPA & 0.5 & 101 & AAA & 0.75 & 114 & AAA & 0.5 \\
\hline 72 & IMA & 0.75 & 88 & FEI & 0.75 & 102 & AICPA & 1 & 115 & AICPA & 0.75 \\
\hline 73 & AICPA & 1 & 88 & IMA & 0.75 & 102 & FEI & 0.75 & 115 & FEI & 0.25 \\
\hline 73 & IMA & 1 & 89 & AICPA & 1 & 102 & IMA & 1 & 115 & IMA & 0.75 \\
\hline 74 & AICPA & 0.75 & 89 & FEI & 1 & 103 & FEI & 1 & 115 & CFA Inst & 0.25 \\
\hline 74 & FEI & 0 & 89 & IMA & 1 & 103 & IMA & 1 & 115 & AAA & 0.5 \\
\hline 74 & IMA & 0.5 & 89 & AAA & 0.75 & 104 & AICPA & 1 & 116 & AICPA & 0.75 \\
\hline 75 & IMA & 1 & 90 & AICPA & 0.75 & 104 & FEI & 0.75 & 116 & FEI & 0.5 \\
\hline 76 & AICPA & 0.5 & 90 & FEI & 0.5 & 104 & IMA & 0.75 & 116 & IMA & 0.5 \\
\hline 76 & FEI & 0.75 & 90 & IMA & 1 & 104 & CFA Inst & 1 & 116 & AAA & 0.5 \\
\hline 76 & IMA & 1 & 91 & AICPA & 0.5 & 105 & AICPA & 0.75 & 117 & AICPA & 0.75 \\
\hline 77 & AICPA & 0 & 91 & FEI & 0.75 & 105 & FEI & 0.75 & 117 & IMA & 0 \\
\hline 77 & FEI & 1 & 91 & IMA & 0.75 & 105 & IMA & 0.75 & 117 & AAA & 0.25 \\
\hline 77 & IMA & 1 & 92 & AICPA & 0.75 & 105 & CFA Inst & 1 & 118 & AICPA & 1 \\
\hline 77 & CFA Inst & 0 & 92 & FEI & 0.5 & 106 & AICPA & 0.5 & 118 & FEI & 1 \\
\hline 77 & AAA & 0 & 92 & IMA & 0.75 & 106 & FEI & 0.25 & 118 & IMA & 1 \\
\hline 78 & AICPA & 0.75 & 93 & AICPA & 0.75 & 106 & IMA & 0.5 & 118 & CFA Inst & 0 \\
\hline 78 & FEI & 0 & 93 & FEI & 0.75 & 106 & CFA Inst & 1 & 118 & AAA & 0.25 \\
\hline
\end{tabular}




\begin{tabular}{|c|c|c|c|c|c|c|c|c|c|c|c|}
\hline$\overline{\text { SFAS }}$ & Sponsor & $P O S_{m}$ & SFAS & Sponsor & $P O S_{m}$ & SFAS & Sponsor & $P O S_{m}$ & SFAS & Sponsor & $\mathrm{POS}_{m}$ \\
\hline 119 & AICPA & 0.75 & 129 & IMA & 1 & 141 & AICPA & 0.75 & 151 & CFA Inst & 0.75 \\
\hline 119 & FEI & 0.5 & 129 & CFA Inst & 1 & 141 & FEI & 0.25 & 153 & AICPA & 0.75 \\
\hline 119 & IMA & 0.75 & 130 & AICPA & 0.25 & 141 & CFA Inst & 0.75 & 153 & FEI & 0.75 \\
\hline 119 & CFA Inst & 0.75 & 130 & FEI & 0.25 & 141 & AAA & 0.5 & 153 & IMA & 0.5 \\
\hline 119 & AAA & 1 & 130 & IMA & 0 & 142 & AICPA & 0 & 153 & CFA Inst & 0.75 \\
\hline 120 & AICPA & 1 & 130 & CFA Inst & 0.75 & 142 & FEI & 0.25 & $123 \mathrm{R}$ & AICPA & 0.5 \\
\hline 120 & FEI & 0.75 & 130 & AAA & 1 & 142 & IMA & 0.5 & $123 \mathrm{R}$ & FEI & 0.5 \\
\hline 120 & CFA Inst & 1 & 131 & AICPA & 0.25 & 142 & CFA Inst & 0.5 & $123 \mathrm{R}$ & IMA & 0.25 \\
\hline 121 & AICPA & 0.75 & 131 & FEI & 0 & 142 & AAA & 0.5 & $123 \mathrm{R}$ & CFA Inst & 0.75 \\
\hline 121 & FEI & 0.75 & 131 & IMA & 1 & 143 & AICPA & 0.5 & $123 \mathrm{R}$ & AAA & 0.75 \\
\hline 121 & IMA & 1 & 131 & CFA Inst & 0.75 & 143 & IMA & 0.25 & 154 & AICPA & 0.75 \\
\hline 121 & CFA Inst & 0.75 & 132 & AICPA & 0.75 & 143 & CFA Inst & 0.75 & 154 & FEI & 0.25 \\
\hline 122 & AICPA & 0.75 & 132 & IMA & 0.25 & 144 & AICPA & 0.5 & 154 & IMA & 0.75 \\
\hline 122 & FEI & 0.5 & 132 & CFA Inst & 1 & 144 & FEI & 0.5 & 154 & CFA Inst & 0.75 \\
\hline 122 & IMA & 0.5 & 132 & AAA & 0.75 & 144 & CFA Inst & 0.75 & 154 & AAA & 0.75 \\
\hline 122 & CFA Inst & 0.75 & 133 & AICPA & 1 & 146 & AICPA & 0.25 & 155 & AICPA & 0.75 \\
\hline 122 & AAA & 0.75 & 133 & FEI & 0.5 & 146 & FEI & 0 & 156 & AICPA & 0.75 \\
\hline 123 & FEI & 0.5 & 133 & IMA & 0.25 & 146 & CFA Inst & 1 & 157 & AICPA & 0.75 \\
\hline 123 & CFA Inst & 0.75 & 133 & CFA Inst & 1 & 147 & AICPA & 0.25 & 157 & FEI & 0 \\
\hline 124 & AICPA & 1 & 134 & AICPA & 1 & 147 & CFA Inst & 0.75 & 157 & IMA & 0.25 \\
\hline 124 & IMA & 1 & 134 & IMA & 0.75 & 148 & FEI & 1 & 157 & CFA Inst & 0.75 \\
\hline 125 & AICPA & 0.5 & 135 & AICPA & 0.75 & 148 & CFA Inst & 0.5 & 157 & AAA & 0.75 \\
\hline 125 & FEI & 0.25 & 135 & FEI & 0.25 & 149 & AICPA & 0.75 & 158 & AICPA & 0.75 \\
\hline 125 & IMA & 0.5 & 136 & AICPA & 0.75 & 149 & CFA Inst & 0.5 & 158 & FEI & 0.5 \\
\hline 125 & CFA Inst & 0.75 & 136 & AAA & 0.75 & 150 & AICPA & 0 & 158 & IMA & 0.75 \\
\hline 125 & AAA & 0.75 & 137 & AICPA & 1 & 150 & FEI & 0 & 158 & CFA Inst & 1 \\
\hline 126 & AICPA & 1 & 137 & FEI & 1 & 150 & IMA & 0 & 158 & AAA & 1 \\
\hline 126 & IMA & 1 & 137 & IMA & 1 & 150 & CFA Inst & 1 & 159 & AICPA & 1 \\
\hline 127 & AICPA & 1 & 137 & CFA Inst & 1 & 150 & AAA & 0.5 & 159 & IMA & 1 \\
\hline 127 & IMA & 1 & 138 & AICPA & 1 & $132 \mathrm{R}$ & AICPA & 0.25 & 159 & CFA Inst & 0.5 \\
\hline 128 & AICPA & 1 & 138 & FEI & 1 & $132 \mathrm{R}$ & FEI & 0.25 & 159 & AAA & 0.25 \\
\hline 128 & FEI & 0.5 & 138 & IMA & 1 & $132 \mathrm{R}$ & IMA & 0.25 & $141 \mathrm{R}$ & AICPA & 0.25 \\
\hline 128 & IMA & 0.75 & 138 & CFA Inst & 1 & $132 \mathrm{R}$ & CFA Inst & 0 & $141 \mathrm{R}$ & FEI & 0 \\
\hline 128 & CFA Inst & 1 & 140 & AICPA & 0.75 & 151 & AICPA & 0.75 & $141 \mathrm{R}$ & IMA & 0 \\
\hline 129 & AICPA & 1 & 140 & FEI & 0.75 & 151 & FEI & 0.5 & $141 \mathrm{R}$ & CFA Inst & 0.75 \\
\hline 129 & FEI & 1 & 140 & CFA Inst & 0.75 & 151 & IMA & 0.25 & 160 & AICPA & 0.25 \\
\hline
\end{tabular}

Appendix 2 provides the position of sponsoring organization $m$ on each comment letter for each of the 163 standards from SFAS 1 through SFAS 160 (inclusive of revisions), where available. I classify sponsors' comment letter positions into five categories: strongly oppose $\left(P O S_{m}=0\right)$, lean oppose $(0.25)$, neither support nor oppose $(0.5)$, lean support $(0.75)$, and strongly support $\left(P O S_{m}=1\right)$. Refer to the supplementary internet appendix for a description of the coding process. 
APPENDIX 3. Representativeness and $C F \_R e f s$ for all standards, SFAS 1 - SFAS 160

\begin{tabular}{|c|c|c|c|c|c|c|c|c|c|c|c|}
\hline SFAS & $\boldsymbol{R}_{t}$ & $C F \_R e f s_{t}$ & SFAS & $\boldsymbol{R}_{t}$ & $C F \_R e f s_{t}$ & SFAS & $\boldsymbol{R}_{t}$ & $C F_{-} R e f s_{t}$ & SFAS & $\boldsymbol{R}_{t}$ & $C F \_R e f s$ \\
\hline 1 & 0.78 & 0 & 42 & 0.88 & 0 & 83 & 1.00 & 0 & 124 & 0.60 & 1.79 \\
\hline 2 & 0.77 & 0 & 43 & 0.94 & 0 & 84 & 0.78 & 0 & 125 & 0.64 & 1.95 \\
\hline 3 & 0.83 & 0 & 44 & 0.56 & 0 & 85 & 1.00 & 0 & 126 & 1.00 & 0 \\
\hline 4 & 0.90 & 0 & 45 & & 0 & 86 & 0.83 & 0 & 127 & 1.00 & 0 \\
\hline 5 & 0.77 & 0 & 46 & & 0 & 87 & 0.98 & 1.79 & 128 & 0.88 & 0.69 \\
\hline 6 & 1.00 & 0 & 47 & 0.75 & 0.69 & 88 & 0.81 & 0.69 & 129 & 1.00 & 0 \\
\hline 7 & 1.00 & 0 & 48 & & 0 & 89 & 0.71 & 0 & 130 & 0.68 & 2.89 \\
\hline 8 & 0.85 & 0 & 49 & & 0 & 90 & 0.65 & 1.10 & 131 & 0.58 & 1.39 \\
\hline 9 & 1.00 & 0 & 50 & 1.00 & 0 & 91 & 0.80 & 0.69 & 132 & 0.64 & 1.10 \\
\hline 10 & 1.00 & 0 & 51 & 0.85 & 0 & 92 & 0.90 & 0 & 133 & 0.75 & 2.08 \\
\hline 11 & 0.80 & 0 & 52 & 0.84 & 1.39 & 93 & 0.67 & 2.56 & 134 & 0.90 & 0 \\
\hline 12 & 0.83 & 0 & 53 & 0.55 & 0 & 94 & 0.58 & 2.20 & 135 & 0.55 & 0 \\
\hline 13 & 1.00 & 0 & 54 & 1.00 & 0 & 95 & 0.71 & 2.30 & 136 & 0.75 & 1.79 \\
\hline 14 & 0.78 & 0 & 55 & 0.75 & 0 & 96 & 0.71 & 1.79 & 137 & 0.67 & 0 \\
\hline 15 & 0.98 & 0 & 56 & & 0 & 97 & 0.83 & 1.39 & 138 & 0.67 & 1.10 \\
\hline 16 & 0.80 & 0 & 57 & 0.81 & 1.79 & 98 & 0.67 & 0 & 139 & & 0 \\
\hline 17 & 1.00 & 0 & 58 & 0.91 & 0 & 99 & 0.92 & 0 & 140 & 0.95 & 2.08 \\
\hline 18 & 1.00 & 0 & 59 & 1.00 & 0.69 & 100 & 1.00 & 0 & 141 & 0.54 & 3.37 \\
\hline 19 & 0.75 & 0 & 60 & 0.63 & 0 & 101 & 0.42 & 1.39 & 142 & 0.21 & 2.83 \\
\hline 20 & 0.60 & 0 & 61 & 0.81 & 0 & 102 & 0.85 & 0 & 143 & 0.40 & 3.33 \\
\hline 21 & 0.80 & 0 & 62 & 1.00 & 0 & 103 & 1.00 & 0 & 144 & 0.54 & 2.89 \\
\hline 22 & 0.95 & 0 & 63 & 0.95 & 0.69 & 104 & 0.90 & 0 & 145 & & 0 \\
\hline 23 & 0.80 & 0 & 64 & 0.94 & 0 & 105 & 0.75 & 2.20 & 146 & 0.46 & 3.00 \\
\hline 24 & 0.60 & 0 & 65 & 0.81 & 0 & 106 & 0.50 & 2.56 & 147 & 0.38 & 0.69 \\
\hline 25 & 0.75 & 0.69 & 66 & 0.69 & 0 & 107 & 0.68 & 1.39 & 148 & 0.83 & 0 \\
\hline 26 & 1.00 & 0 & 67 & 0.94 & 0 & 108 & & 0 & 149 & 0.69 & 1.61 \\
\hline 27 & 0.88 & 0 & 68 & 0.84 & 1.10 & 109 & 0.75 & 2.56 & 150 & 0.36 & 1.95 \\
\hline 28 & 0.78 & 0 & 69 & 0.84 & 0 & 110 & 1.00 & 0 & $132 \mathrm{R}$ & 0.21 & 1.10 \\
\hline 29 & 0.31 & 0 & 70 & 0.88 & 0 & 111 & 1.00 & 0 & 151 & 0.63 & 0 \\
\hline 30 & 1.00 & 0 & 71 & 0.94 & 1.61 & 112 & 0.85 & 0 & 152 & & 0 \\
\hline 31 & 0.81 & 0 & 72 & 0.66 & 1.10 & 113 & 0.20 & 1.10 & 153 & 0.71 & 0.69 \\
\hline 32 & 0.81 & 0 & 73 & 1.00 & 0 & 114 & 0.96 & 0.69 & $123 \mathrm{R}$ & 0.54 & 2.30 \\
\hline 33 & 0.77 & 1.39 & 74 & 0.88 & 0.69 & 115 & 0.79 & 1.10 & 154 & 0.68 & 1.10 \\
\hline 34 & 0.69 & 0.69 & 75 & & 0 & 116 & 0.79 & 2.89 & 155 & 0.75 & 0 \\
\hline 35 & 0.73 & 0.69 & 76 & 0.91 & 1.10 & 117 & 0.42 & 2.71 & 156 & 0.75 & 1.10 \\
\hline 36 & 0.80 & 0 & 77 & 0.50 & 1.61 & 118 & 0.96 & 0 & 157 & 0.57 & 3.00 \\
\hline 37 & 1.00 & 0 & 78 & 0.94 & 0 & 119 & 0.75 & 0.69 & 158 & 0.79 & 1.39 \\
\hline 38 & 0.69 & 0 & 79 & 1.00 & 0.69 & 120 & 0.92 & 0 & 159 & 0.89 & 0 \\
\hline 39 & 0.28 & 0.69 & 80 & 0.84 & 0 & 121 & 0.88 & 1.10 & $141 \mathrm{R}$ & 0.45 & 2.71 \\
\hline 40 & 0.19 & 0 & 81 & 0.73 & 0 & 122 & 0.68 & 0.69 & 160 & 0.25 & 1.39 \\
\hline 41 & 0.28 & 0 & 82 & 1.00 & 0 & 123 & 0.92 & 1.95 & & & \\
\hline
\end{tabular}

Appendix 3 provides the values of Representativeness and $C F \_$Refs for each of the 163 standards from SFAS 1 through SFAS 160 (inclusive of revisions), where available. Standards are presented in chronological order.

Representativeness measures the diversity of FASB positions on standard $t$ relative to sponsors' positions, while $C F_{-}$Refs measures the frequency of each standard's authoritative references to the conceptual framework.

Additional detail regarding each variable is included within Appendix 1. 
FIGURE 1. Relationship between the FASB, FAF, constituent sponsoring organizations, and standard setting constituent groups ${ }^{\mathrm{a}}$

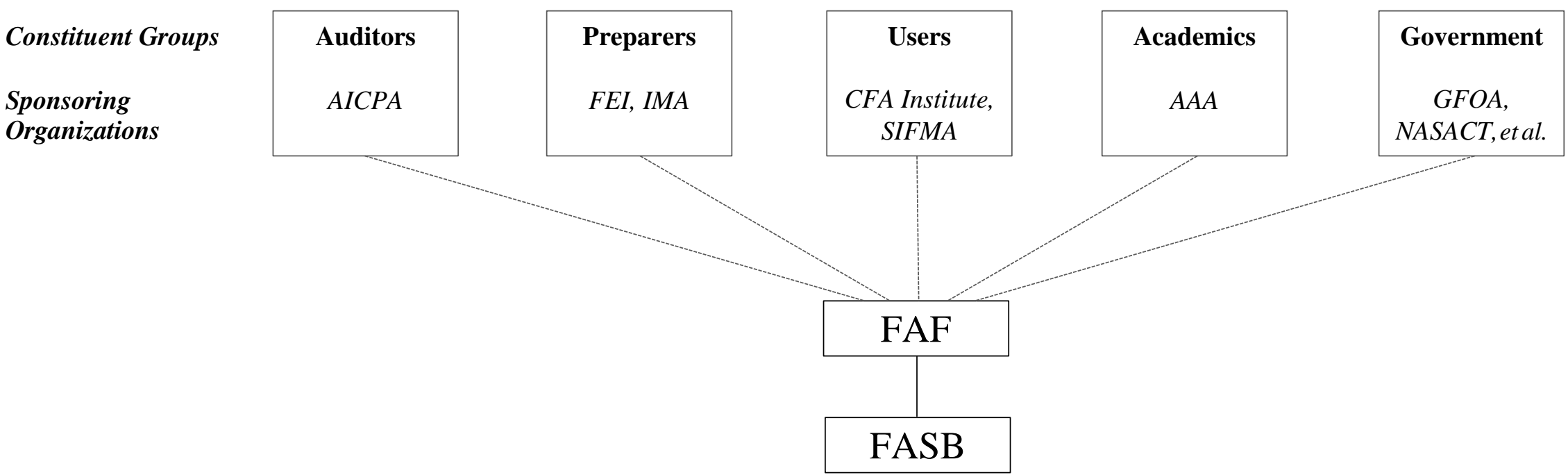

Figure 1 illustrates the relationship between standard setting constituent groups, their sponsoring organizations, the FAF, and the FASB, as described in section 2.1. This structure has undergone revision through time; SIFMA was added in 1976, while the Government organizations were added in 1984 (Gore 1992, 142).

\footnotetext{
${ }^{a}$ Full names of the sponsoring organizations that are referred to in shorthand notation above are as follows: AICPA (American Institute of Certified Public Accountants), FEI (Financial Executives Institute), IMA (Institute of Management Accountants; formerly named NAA - National Association of Accountants), SIFMA (Securities Industry and Financial Markets Association; formerly named SIA - Securities Industry Association), AAA (American Accounting Association), GFOA (Government Finance Officers Association), and NASACT (National Association of State Auditors, Comptrollers and Treasurers). The CFA Institute was formerly named AIMR (Association for Investment Management and Research), and is a successor organization to the Financial Analysts Federation. The Government constituency is represented by a number of sponsors in addition to GFOA and NASACT; due to space considerations I do not reproduce the full list.
} 
FIGURE 2. Average number of times each standard cites the $\mathrm{CF}$ for authoritative guidance

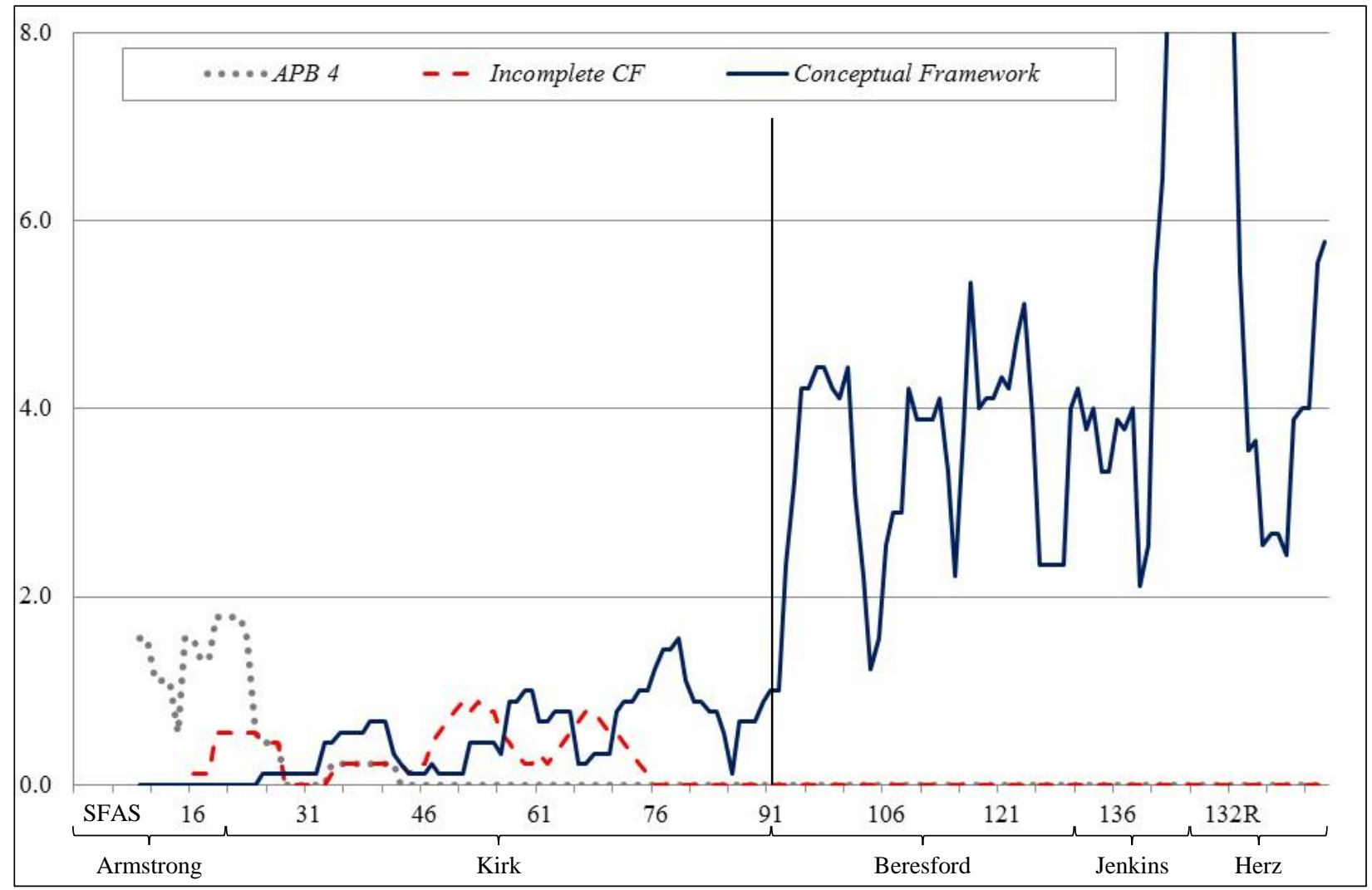

Figure 2 depicts time-series variation in the frequency of standards' authoritative references to the conceptual framework. Standards are presented in chronological order. The names shown are the last names of the FASB Chairperson during each bracketed period: Marshall S. Armstrong, Donald J. Kirk, Dennis R. Beresford, Edmund L. Jenkins, and Robert H. Herz.

The rolling averages are calculated over the prior nine standards. The dotted line denotes authoritative references to APB Statement \#4. The dashed line denotes references that the Board was somehow limited because the conceptual framework was incomplete. The solid line denotes authoritative references to the conceptual framework. In some instances, this exceeds 8.0, which values are not visible on the graph. The peak value of the rolling average is 12.9 , relating to SFAS 146. Note that these are the raw number of references, not the transformed (logged) values used in variable CF_Refs; see Appendix 1 for detail.

The vertical line represents SFAS 91, which delineates the Pre-CF from the $C F$ regime. 
FIGURE 3. Positions of FASB members and sponsoring organizations on a standard

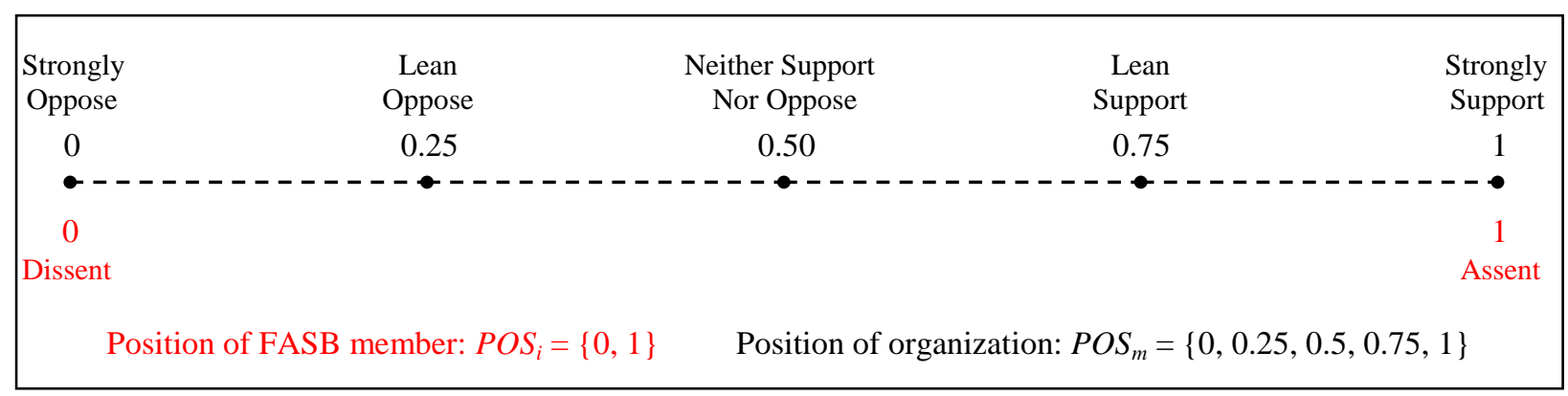

Figure 3 depicts the position of individual FASB member $i\left(P O S_{i}\right)$ and sponsor $m\left(P O S_{m}\right)$ on a standard. I determine positions of FASB members by their vote on each standard (assent or dissent). I operationalize the position of each constituent group as the average of the position taken by the group's sponsor(s) in comment letters to the final Exposure Draft related to each standard. I classify these positions into five categories (based upon whether the letter opposes or supports the related ED) per the descriptions provided above the scale. The values provided above the scale indicate how each category was converted into a $\mathrm{POS}_{m}$ value.

\section{FIGURE 4. Illustration of inside dissent and outside dissent}

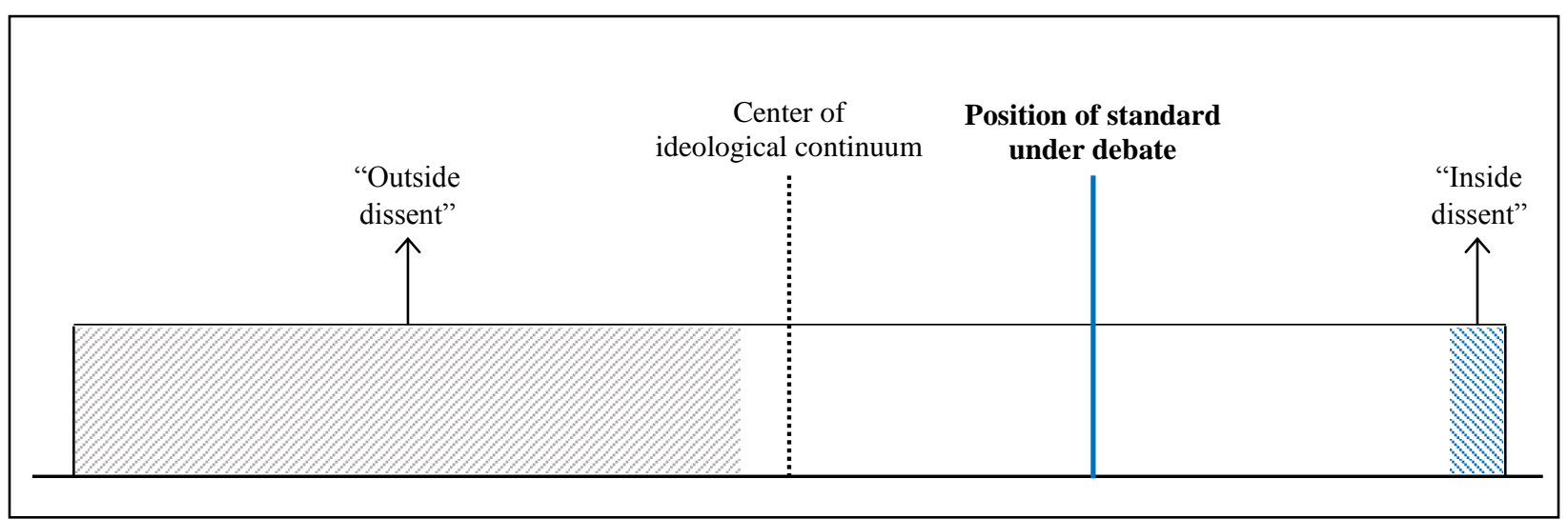

Figure 4 illustrates two types of dissent. The horizontal line represents an ideological continuum, for example one's preference for fair value accounting (with increasing preference for fair values moving rightward). A simplifying assumption is made that standard-setters are uniformly distributed across the continuum. In this example, a fair value standard is up for debate, indicated by the solid vertical line being positioned to the right of center. This standard is opposed by a majority of standard-setters on the left of the continuum (outside dissent), but is supported by those standard-setters on the left whose positions are closest to the center (because the position of the standard is sufficiently near to their preferred position). The standard is also supported by a majority of standard-setters on the right; however, it is opposed by the segment of standard-setters farthest to the right because the position of the standard is sufficiently far from their preferred position (inside dissent). Inside dissent for a particular preference (e.g., fair value accounting) can only be observed on a standard favoring that preference.

The key intuition of this depiction is that observing a dissenting vote does not distinguish a standard-setter whose position is in the shaded area on the left from one whose position is in the shaded area on the right. 
FIGURE 5. FASB dissent, constituent dissent, and standard type for matched sample

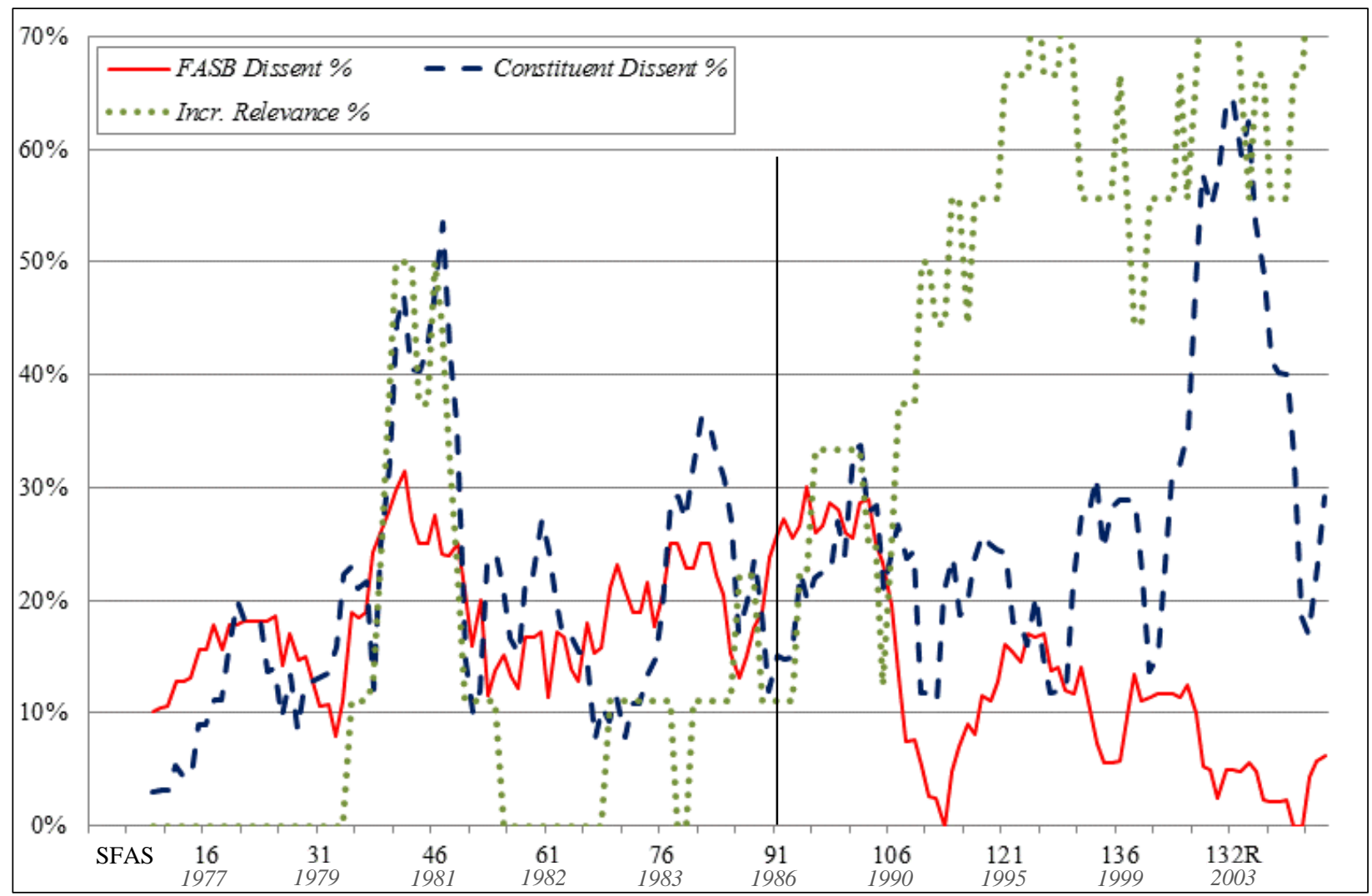

Figure 5 depicts time-series variation in FASB dissent, constituent dissent, and standards that increase accounting relevance. Refer to Appendix 1 for variable definitions. The rolling averages are calculated over the prior nine standards. The solid line represents FASB dissent percentage for the matched sample. The dashed line represents constituent dissent percentage for the matched sample. The dotted line represents the indicator variable Inc_Relv, which identifies standards increasing accounting relevance. In some instances, this exceeds $70 \%$, which values are not visible on the graph. The peak value of the rolling average is 89\%, relating to the both SFAS 148 and SFAS 149.

The vertical line represents SFAS 91, which delineates the Pre-CF from the $C F$ regime. 
TABLE 1. Descriptive statistics for standard-level variables

Panel A. Summary statistics for full sample

\begin{tabular}{|c|c|c|c|c|c|c|c|c|}
\hline Variable & Observations & Mean & Median & $\begin{array}{c}\text { Standard } \\
\text { Deviation }\end{array}$ & Minimum & $25 \%$ & $75 \%$ & Maximum \\
\hline Representativeness & 153 & 0.766 & 0.800 & 0.201 & 0.188 & 0.667 & 0.917 & 1.000 \\
\hline FASB Dissent & 163 & 0.138 & 0.143 & 0.153 & 0.000 & 0.000 & 0.286 & 0.429 \\
\hline$P O S_{j \_}$Auditor & 148 & 0.708 & 0.750 & 0.261 & 0.000 & 0.500 & 1.000 & 1.000 \\
\hline POS $S_{j}$ Preparer & 149 & 0.701 & 0.875 & 0.325 & 0.000 & 0.500 & 1.000 & 1.000 \\
\hline $\mathrm{POS}_{j_{-}}$User & 78 & 0.702 & 0.750 & 0.312 & 0.000 & 0.500 & 1.000 & 1.000 \\
\hline$P O S_{j \_}$Academic & 46 & 0.707 & 0.750 & 0.285 & 0.000 & 0.500 & 1.000 & 1.000 \\
\hline AvgTenure & 163 & 2.917 & 2.890 & 0.676 & 0.000 & 2.497 & 3.434 & 3.989 \\
\hline LagReturn & 163 & 0.123 & 0.135 & 0.177 & -0.344 & -0.008 & 0.252 & 0.651 \\
\hline ED_Frequency & 163 & 2.541 & 2.485 & 0.585 & 0.000 & 2.197 & 3.045 & 3.584 \\
\hline$C F \_R e f s$ & 163 & 0.651 & 0.000 & 0.933 & 0.000 & 0.000 & 1.099 & 3.367 \\
\hline Inc_Relv & 160 & 0.306 & 0.000 & 0.462 & 0.000 & 0.000 & 1.000 & 1.000 \\
\hline
\end{tabular}

Panel B. Summary statistics for the Pre-CF and $C F$ regimes

\begin{tabular}{|c|c|c|c|c|c|c|c|c|c|c|}
\hline \multirow{3}{*}{$\begin{array}{l}\text { Variable } \\
\text { Representativeness }\end{array}$} & \multicolumn{4}{|c|}{ Pre-CF regime } & \multicolumn{4}{|c|}{ CF regime } & \multirow{2}{*}{\multicolumn{2}{|c|}{$\begin{array}{l}\text { Difference in } \\
\text { Means }\end{array}$}} \\
\hline & Observations & Mean & Median & $\begin{array}{l}\text { Standard } \\
\text { Deviation }\end{array}$ & Observations & Mean & Median & $\begin{array}{l}\text { Standard } \\
\text { Deviation }\end{array}$ & & \\
\hline & 85 & 0.817 & 0.833 & 0.176 & 68 & 0.703 & 0.708 & 0.213 & -0.114 & $* * *$ \\
\hline FASB Dissent & 91 & 0.169 & 0.143 & 0.163 & 72 & 0.098 & 0.000 & 0.129 & -0.071 & $* * *$ \\
\hline$P O S_{j} \_$Auditor & 83 & 0.729 & 0.750 & 0.241 & 65 & 0.681 & 0.750 & 0.285 & -0.048 & \\
\hline POS $S_{j}$ Preparer & 87 & 0.773 & 1.000 & 0.309 & 62 & 0.601 & 0.625 & 0.323 & -0.172 & $* * *$ \\
\hline $\mathrm{POS}_{j_{-}}$User & 30 & 0.617 & 0.750 & 0.387 & 48 & 0.755 & 0.750 & 0.245 & 0.139 & $*$ \\
\hline$P O S_{j \_}$Academic & 18 & 0.792 & 1.000 & 0.312 & 28 & 0.652 & 0.750 & 0.258 & -0.140 & \\
\hline AvgTenure & 91 & 3.083 & 3.296 & 0.831 & 72 & 2.706 & 2.799 & 0.296 & -0.377 & $* * *$ \\
\hline LagReturn & 91 & 0.099 & 0.067 & 0.198 & 72 & 0.152 & 0.174 & 0.142 & 0.052 & $*$ \\
\hline ED_Frequency & 91 & 2.817 & 2.890 & 0.631 & 72 & 2.192 & 2.197 & 0.231 & -0.625 & $* * *$ \\
\hline$C F_{-} R e f s$ & 91 & 0.237 & 0.000 & 0.476 & 72 & 1.174 & 1.099 & 1.095 & 0.937 & $* * *$ \\
\hline Inc_Relv & 90 & 0.089 & 0.000 & 0.286 & 70 & 0.586 & 1.000 & 0.496 & 0.497 & $* * *$ \\
\hline
\end{tabular}


Panel C.Summary statistics for Inc_Relv and non-Inc_Relv standards

\begin{tabular}{|c|c|c|c|c|c|c|c|c|c|c|}
\hline \multirow{3}{*}{$\frac{\text { Variable }}{\text { Representativeness }}$} & \multirow{3}{*}{$\begin{array}{c}\text { Observations } \\
102\end{array}$} & \multicolumn{3}{|c|}{ Inc_Relv $=0$} & \multirow{3}{*}{$\begin{array}{c}\text { Observations } \\
48\end{array}$} & \multicolumn{3}{|c|}{ Inc_Relv $=1$} & \multirow{2}{*}{\multicolumn{2}{|c|}{$\begin{array}{l}\text { Difference in } \\
\text { Means }\end{array}$}} \\
\hline & & Mean & Median & $\begin{array}{l}\text { Standard } \\
\text { Deviation }\end{array}$ & & Mean & Median & $\begin{array}{l}\text { Standard } \\
\text { Deviation }\end{array}$ & & \\
\hline & & 0.822 & 0.833 & 0.156 & & 0.651 & 0.708 & 0.234 & -0.171 & $* * *$ \\
\hline FASB Dissent & 111 & 0.144 & 0.143 & 0.156 & 49 & 0.123 & 0.000 & 0.149 & -0.020 & \\
\hline$P O S_{j \_}$Auditor & 101 & 0.745 & 0.750 & 0.237 & 45 & 0.633 & 0.750 & 0.295 & -0.112 & $* *$ \\
\hline POS $_{j_{-}}$Preparer & 104 & 0.775 & 1.000 & 0.304 & 42 & 0.521 & 0.500 & 0.292 & -0.254 & $* * *$ \\
\hline $\mathrm{POS}_{j_{-}}$User & 39 & 0.744 & 0.750 & 0.346 & 38 & 0.658 & 0.750 & 0.275 & -0.086 & \\
\hline$P O S_{j \_}$Academic & 27 & 0.722 & 0.750 & 0.328 & 19 & 0.684 & 0.750 & 0.218 & -0.038 & \\
\hline AvgTenure & 111 & 2.970 & 2.914 & 0.766 & 49 & 2.808 & 2.858 & 0.417 & -0.162 & $*$ \\
\hline LagReturn & 111 & 0.102 & 0.097 & 0.184 & 49 & 0.165 & 0.173 & 0.157 & 0.064 & $* *$ \\
\hline ED_Frequency & 111 & 2.635 & 2.565 & 0.631 & 49 & 2.337 & 2.303 & 0.410 & -0.298 & $* * *$ \\
\hline CF_Refs & 111 & 0.375 & 0.000 & 0.711 & 49 & 1.262 & 1.099 & 1.055 & -0.887 & $* * *$ \\
\hline
\end{tabular}

Panel D. Pearson and Spearman correlations

\begin{tabular}{|c|c|c|c|c|c|c|c|c|c|c|c|}
\hline & $R_{t}$ & $\begin{array}{c}\text { FASB } \\
\text { Dissent }\end{array}$ & $\begin{array}{l}P O S_{j} \\
\text { Audit }\end{array}$ & $\begin{array}{c}\text { POS }_{j} \\
\text { Preparer }\end{array}$ & $\begin{array}{l}P_{\text {POS }} \\
\text { User }\end{array}$ & $\begin{array}{c}\text { POS }_{j} \\
\text { Academic }\end{array}$ & $\begin{array}{c}\text { Avg } \\
\text { Tenure }\end{array}$ & $\begin{array}{c}\text { Lag } \\
\text { Return }\end{array}$ & $\begin{array}{l}\text { ED_ } \\
\text { Freq }\end{array}$ & $\begin{array}{l}\mathrm{CF}_{-} \\
\text {Refs }\end{array}$ & $\begin{array}{l}\text { Inc } \\
\text { Relv }\end{array}$ \\
\hline$R_{t}$ & & 0.06 & $0.68 * * *$ & $0.51 * * *$ & $0.20 *$ & 0.13 & $0.14 *$ & -0.04 & $0.15^{*}$ & $-0.46 * * *$ & $-0.40 * * *$ \\
\hline FASB Dissent & $0.42 * *$ & & -0.10 & -0.11 & $-0.31 * * *$ & $-0.33^{* *}$ & $0.13 *$ & 0.01 & $0.23 * * *$ & -0.05 & -0.06 \\
\hline$P O S_{j \_}$Audit & $0.64 * * *$ & -0.02 & & $0.43^{* * *}$ & 0.12 & 0.15 & 0.02 & 0.04 & 0.03 & $-0.36^{* * *}$ & $-0.20 * *$ \\
\hline$P O S_{j \_}$Preparer & $0.49 * * *$ & 0.12 & $0.48 * * *$ & & 0.05 & 0.05 & 0.06 & -0.02 & 0.04 & $-0.51 * * *$ & $-0.36 * * *$ \\
\hline$P O S_{j_{-}}$User & 0.09 & $-0.42 * *$ & -0.01 & -0.05 & & $0.65 * * *$ & $-0.24 * *$ & 0.05 & $-0.38 * * *$ & 0.01 & -0.14 \\
\hline$P O S_{j \_}$Academic & 0.29 & $-0.34 *$ & 0.08 & 0.10 & $0.58 * * *$ & & -0.22 & 0.18 & -0.10 & -0.15 & -0.07 \\
\hline AvgTenure & -0.08 & $0.53 * * *$ & -0.30 & -0.14 & $-0.52 * * *$ & -0.30 & & $0.21 * * *$ & $0.78 * * *$ & -0.02 & -0.11 \\
\hline LagReturn & -0.23 & 0.08 & -0.10 & $-0.46 * *$ & -0.09 & 0.00 & 0.19 & & $0.20 * *$ & $0.19 * *$ & $0.17 * *$ \\
\hline ED_Frequency & 0.06 & $0.48 * * *$ & -0.17 & -0.09 & $-0.37 * *$ & -0.04 & $0.47 * * *$ & $0.40 * *$ & & $-0.15^{* *}$ & $-0.23 * * *$ \\
\hline CF_Refs & $-0.74 * * *$ & -0.04 & $-0.64 * * *$ & $-0.63 * * *$ & -0.18 & -0.24 & $0.33^{*}$ & $0.45^{* *}$ & 0.08 & & $0.44 * * *$ \\
\hline Inc_Relv & $-0.38 * *$ & -0.25 & 0.00 & -0.24 & -0.16 & -0.24 & $0.31 *$ & 0.22 & -0.21 & $0.45 * *$ & \\
\hline
\end{tabular}


Table 1 provides descriptive statistics for key standard-level variables as well as $P O S_{j}$ values for each constituency. Panel A provides summary statistics for the full sample, while Panel B (Panel C) provides separate statistics for the Pre-CF and CF regimes (for Inc_Relv and non-Inc_Relv standards). Panel D provides the correlations between each variable. Pearson (Spearman) correlations are above (below) the diagonal.

Refer to Appendix 1 for variable definitions. Representativeness $\left(R_{t}\right)$ measures the diversity of FASB positions on standard $t$ relative to sponsors' positions. $F A S B$ Dissent is the dissent percentage of the FASB vote on each standard. $P O S_{j}$ represents the position of constituent group $j$ on each standard. AvgTenure measures the experience level of the FASB members voting on each standard. LagReturn is the lagged one-year return on the CRSP value-weighted index as of the date of the final ED to each standard. ED Frequency is the log of the number of Exposure Drafts that ultimately became standards that were issued in the two years prior to the date of the final ED to each standard. $C F \_R e f s$ identifies the frequency of authoritative references to the framework on each standard. Inc_Relv is an indicator variable which identifies standards that increase accounting relevance.

Differences in Panels B and C are calculated using a Welch's t-test for unpaired data with unequal variances.

Significance levels based on two-tailed p-values: $(*) 10 \%$ level, $(* *) 5 \%$ level, $(* * *) 1 \%$ level 
TABLE 2. Summary data for matched sample in the Pre-CF and $C F$ regimes

Panel A. FASB dissents and constituent dissents - Difference-in-differences

\begin{tabular}{|c|c|c|c|}
\hline & Pre-CF Regime & $C F$ Regime & \\
\hline $\begin{array}{r}\text { Matched } \\
F A S B\end{array}$ & 71 / 390 & 42 / 372 & $-6.9 \% * * *$ \\
\hline Dissents & $18.2 \%$ & $11.3 \%$ & $(-2.71)$ \\
\hline $\begin{array}{r}\text { Constituent } \\
\text { Dissents }\end{array}$ & $\begin{array}{l}70 / 390 \\
\mathbf{1 7 . 9 \%}\end{array}$ & $\begin{array}{c}106.5 / 372 \\
\mathbf{2 8 . 6 \%}\end{array}$ & $\begin{array}{c}10.7 \% * * * \\
(3.89)\end{array}$ \\
\hline$\%$ Difference & $-0.3 \%$ & $17.3 \% * * *$ & $-17.6 \% * * *$ \\
\hline (t-stat) & $(-0.09)$ & (5.94) & $(-4.34)$ \\
\hline
\end{tabular}

Panel B. Analysis of submission frequency by constituent group

\begin{tabular}{|c|c|c|c|c|}
\hline $\begin{array}{l}\text { Constituent } \\
\text { Group }\end{array}$ & $\begin{array}{c}\text { Pre-CF Regime } \\
\text { Matched Votes } \\
\text { Constituent Dissents } \\
\end{array}$ & $\begin{array}{c}\text { CF Regime } \\
\text { Matched Votes } \\
\text { Constituent Dissents }\end{array}$ & Difference & (t-stat) \\
\hline \multirow{2}{*}{ Auditors } & $271 / 295(92 \%)$ & $192 / 213(90 \%)$ & $-1.7 \%$ & $(-0.66)$ \\
\hline & $41.0 / 271(15 \%)$ & $46.0 / 192(24 \%)$ & $8.8 \% * * *$ & $(2.63)$ \\
\hline \multirow{2}{*}{ Preparers } & 90 / $94(96 \%)$ & $121 / 141(86 \%)$ & $-9.9 \% * * *$ & $(-2.75)$ \\
\hline & $18.5 / 90(21 \%)$ & $49.0 / 121(40 \%)$ & $19.9 \% * * *$ & $(3.45)$ \\
\hline \multirow{2}{*}{ Users } & $11 / 63(17 \%)$ & $31 / 43(72 \%)$ & $54.6 \% * * *$ & $(6.48)$ \\
\hline & $7.5 / 11(68 \%)$ & $4 / 31(13 \%)$ & $-55.3 \% * * *$ & $(-3.72)$ \\
\hline \multirow{2}{*}{ Academics } & 18 / $91(20 \%)$ & $28 / 71(39 \%)$ & $19.7 \% * * *$ & $(2.73)$ \\
\hline & $3.0 / 18(17 \%)$ & $7.5 / 28(27 \%)$ & $10.1 \%$ & $(0.88)$ \\
\hline
\end{tabular}

Table 2 expands on the data in Panel B of Table 1. Panel A provides data on FASB and constituent (i.e., sponsor) dissents within a difference-in-differences design, and is used to test Hypothesis $1 \mathrm{~b}$. Panel B provides detail on comment letter submission frequencies and dissent by constituent group in the Pre-CF and $C F$ regimes.

Refer to Appendix 1 for variable definitions. In Panel A, Matched FASB Dissents reflects the total number of FASB member dissents matched to a constituent position. Voting data are hand-collected from each standard. Constituent 
Dissents reflects the total number of sponsor dissents matched to FASB member votes. The left-hand column (righthand column) represents constituent positions matched to votes in the Pre-CF regime ( $C F$ regime).

In Panel B, Pre-CF and CF Matched Votes reflects the total number of matched constituent positions and the total number of FASB votes (inclusive of unmatched votes), respectively, for each constituent group. These data allow for an analysis of the potential effect of unobserved constituent positions due to "missing" comment letters. Constituent Dissents is repeated from Panel A; in Panel B the data are disaggregated by constituent group.

Vertical (horizontal) differences in Panel A are calculated by using a two-sample paired data mean-comparison test (Welch's t-test for unpaired data with unequal variances). The difference-in-differences is calculated as the difference in vertical differences using a Welch's t-test for unpaired data with unequal variances. Differences in Panel B are calculated using a Welch's t-test for unpaired data with unequal variances.

Significance levels based on two-tailed p-values: $\left(^{*}\right) 10 \%$ level, $(* *) 5 \%$ level, $(* * *) 1 \%$ level 
TABLE 3. Effect of standard characteristics on FASB Dissent in Pre-CF and $C F$ regimes

\begin{tabular}{|c|c|c|c|c|c|c|}
\hline $\begin{array}{l}D V= \\
\text { FASB Dissent }\end{array}$ & (1) & (2) & (3) & $(4)^{\dagger}$ & $(5)^{\dagger}$ & $(6)^{\dagger}$ \\
\hline Pre-CF & $\begin{array}{c}0.12 * * * \\
(2.77)\end{array}$ & $\begin{array}{c}0.09 * * \\
(1.97)\end{array}$ & $\begin{array}{c}0.05 \\
(0.84)\end{array}$ & $\begin{array}{c}0.18 * * * \\
(2.82)\end{array}$ & $\begin{array}{l}0.15^{* *} \\
(2.16)\end{array}$ & $\begin{array}{c}0.05 \\
(0.81)\end{array}$ \\
\hline Inc_Relv & & & $\begin{array}{l}-0.04 \\
(-0.67)\end{array}$ & & & $\begin{array}{l}-0.18 * * \\
(-2.15)\end{array}$ \\
\hline Inc_Relv*Pre-CF & & & $\begin{array}{c}0.21 * * \\
(2.22)\end{array}$ & & & $\begin{array}{c}0.27 * * \\
(2.59)\end{array}$ \\
\hline AvgTenure & & $\begin{array}{l}0.05 * \\
(1.68)\end{array}$ & $\begin{array}{c}0.05 \\
(1.48)\end{array}$ & & $\begin{array}{c}0.05 \\
(1.44)\end{array}$ & $\begin{array}{c}0.05 \\
(1.37)\end{array}$ \\
\hline Supermajority & & $\begin{array}{l}-0.04 \\
(-0.76)\end{array}$ & $\begin{array}{l}-0.04 \\
(-0.58)\end{array}$ & & $\begin{array}{l}-0.05 \\
(-0.53)\end{array}$ & $\begin{array}{l}-0.04 \\
(-0.39)\end{array}$ \\
\hline Constant & $\begin{array}{l}-0.02 \\
(-0.43)\end{array}$ & $\begin{array}{l}-0.13 \\
(-1.12)\end{array}$ & $\begin{array}{l}-0.10 \\
(-0.78)\end{array}$ & $\begin{array}{l}-0.10 \\
(-1.37)\end{array}$ & $\begin{array}{l}-0.21 \\
(-1.32)\end{array}$ & $\begin{array}{l}-0.12 \\
(-0.81)\end{array}$ \\
\hline $\begin{array}{l}\text { Inc_Relv[Pre-CF] } \\
{[F \text {-test] }}\end{array}$ & & & $\begin{array}{c}0.16^{* * * *} \\
{[7.55]}\end{array}$ & & & $\begin{array}{c}0.09 * * \\
{[4.81]}\end{array}$ \\
\hline Observations & 163 & 163 & 160 & 163 & 163 & 160 \\
\hline Pseudo $R^{2}$ & $6.0 \%$ & $9.0 \%$ & $11.4 \%$ & $10.0 \%$ & $12.5 \%$ & $16.6 \%$ \\
\hline
\end{tabular}

Table 3 provides results for the estimation of equation 2, and is used for testing Hypotheses 1a and 2a. Columns (1) and (4) estimate a basic version of the equation without any control variables; columns (2) and (5) include control variables; and columns (3) and (6) estimate the full equation. Columns (1), (2), and (3) use FASB Dissent, the dissent percentage of the FASB vote on each standard (total dissents $\div$ total votes). ${ }^{\dagger}$ Columns (4), (5), and (6) are run using an adjusted FASB Dissent metric that converts 'inside' dissents on fair value standards to assents. I use a Tobit regression because the dependent variable FASB Dissent is left-censored at zero.

Pre-CF is an indicator variable equal to one for SFAS 1 through SFAS 91. The variable Inc_Relv is an indicator variable which identifies standards that increase accounting relevance. The reference category is $C F$, an indicator variable (excluded from these regressions) equal to one for SFAS 92 through SFAS 160, so the coefficients on the standalone Inc_Relv variable reflects the CF regime. Inc_Relv[Pre-CF] represents the sum of the two Inc_Relv coefficients, and reflects the impact in the Pre-CF regime. Refer to Appendix 1 for variable definitions.

T-statistics are in brackets underneath each coefficient. Standard errors are heteroscedasticity-robust and clustered by combination. Significance levels based on two-tailed p-values: $\left.{ }^{*}\right) 10 \%$ level, $(* *) 5 \%$ level, $(* * *) 1 \%$ level 
TABLE 4. Effect of standard characteristics on Representativeness in Pre-CF and $C F$ regimes

\begin{tabular}{lcccccc}
\hline $\begin{array}{l}\text { DV }= \\
\text { Representativeness }\end{array}$ & $(1)$ & $(2)$ & $(3)$ & $(4)^{\dagger}$ & $(5)^{\dagger}$ & $(6)^{\dagger}$ \\
\hline Pre-CF & $0.11 * *$ & $0.13^{* *}$ & $0.09^{*}$ & $0.13^{* * *}$ & $0.14^{* *}$ & $0.09^{*}$ \\
& $(2.87)$ & $(2.58)$ & $(1.88)$ & $(3.04)$ & $(2.70)$ & $(1.84)$ \\
Inc_Relv & & & $-0.10^{* *}$ & & & $-0.12^{* * *}$ \\
& & $(-2.67)$ & & & $(-2.92)$ \\
Inc_Relv*Pre-CF & & & $-0.19^{*}$ & & & -0.19 \\
& & $(-1.86)$ & & & $(-1.66)$ \\
AvgTenure & & 0.05 & 0.05 & & 0.05 & 0.05 \\
& & $(1.59)$ & $(1.71)$ & & $(1.42)$ & $(1.55)$ \\
LagReturn & & 0.03 & 0.04 & & 0.03 & 0.05 \\
& & $(0.36)$ & $(0.50)$ & & $(0.43)$ & $(0.58)$ \\
ED_Frequency & & -0.05 & -0.04 & & -0.05 & -0.04 \\
& & $(-1.57)$ & $(-1.20)$ & & $(-1.41)$ & $(-1.09)$ \\
Constant & $0.67 * * *$ & $0.70^{* * *}$ & $0.69 * * *$ & $0.66 * * *$ & $0.71 * * *$ \\
& $(10.61)$ & $(11.30)$ & $(20.04)$ & $(10.39)$ & $(11.21)$ \\
Inc_Relv[Pre-CF] & & & $-0.28 * * *$ & & & $-0.31^{* * *}$ \\
[F-test] & & & {$[9.60]$} & & & {$[9.13]$} \\
Observations & 153 & 153 & 150 & 153 & 153 & 150 \\
Adjusted R ${ }^{2}$ & $7.4 \%$ & $6.8 \%$ & $17.0 \%$ & $8.8 \%$ & $8.1 \%$ & $21.1 \%$ \\
\hline
\end{tabular}

Table 4 provides results for the estimation of equation 3, and is used for testing Hypotheses $1 \mathrm{~b}$ and $2 \mathrm{~b}$. Columns (1) and (4) estimate a basic version of the equation without any control variables; columns (2) and (5) include control variables; and columns (3) and (6) estimate the full equation. Columns (1), (2), and (3) use Representativeness, which measures the diversity of FASB positions on standard $t$ relative to sponsors' positions. 'Columns (4), (5), and (6) are run using an adjusted $R_{t}$ metric that converts 'inside' dissents on fair value standards to assents.

Pre-CF is an indicator variable equal to one for SFAS 1 through SFAS 91. The variable Inc_Relv is an indicator variable which identifies standards that increase accounting relevance. The reference category is $C F$, an indicator variable (excluded from these regressions) equal to one for SFAS 92 through SFAS 160, so the coefficients on the standalone Inc_Relv variable reflects the $C F$ regime. Inc_Relv[Pre-CF] represents the sum of the two Inc_Relv coefficients, and reflects the impact in the Pre-CF regime. Refer to Appendix 1 for variable definitions.

T-statistics are in brackets underneath each coefficient. Standard errors are heteroscedasticity-robust and clustered by combination. Significance levels based on two-tailed p-values: $\left(^{*}\right) 10 \%$ level, $(* *) 5 \%$ level, $(* * *) 1 \%$ level 
TABLE 5. Effect of standard characteristics on constituent dissent in Pre-CF and $C F$ regimes

\begin{tabular}{|c|c|c|c|c|}
\hline $\begin{array}{l}D V= \\
\text { ConstDissent } \%\end{array}$ & (1) & (2) & (3) & (4) \\
\hline Pre-CF & $\begin{array}{l}-0.18^{*} \\
(-1.91)\end{array}$ & $\begin{array}{l}-0.11 \\
(-1.07)\end{array}$ & $\begin{array}{c}0.10 \\
(0.89)\end{array}$ & $\begin{array}{c}0.03 \\
(0.31)\end{array}$ \\
\hline Inc_Relv & & $\begin{array}{l}0.19 \\
(1.56)\end{array}$ & & $\begin{array}{l}0.05 \\
(0.35)\end{array}$ \\
\hline Inc_Relv*Pre-CF & & $\begin{array}{c}0.48 * * * \\
(2.70)\end{array}$ & & $\begin{array}{c}0.62 * * * \\
(3.55)\end{array}$ \\
\hline CF_Refs & & & $\begin{array}{c}0.25 * * * \\
(6.87)\end{array}$ & $\begin{array}{c}0.22 * * * \\
(5.48)\end{array}$ \\
\hline CF_Refs $*$ Pre $-C F$ & & & $\begin{array}{l}-0.01 \\
(-0.11)\end{array}$ & $\begin{array}{c}0.02 \\
(0.16)\end{array}$ \\
\hline Constant & $\begin{array}{c}0.12 \\
(1.60)\end{array}$ & $\begin{array}{c}0.00 \\
(0.06)\end{array}$ & $\begin{array}{c}-0.20 * * \\
(-2.35)\end{array}$ & $\begin{array}{l}-0.19 * * \\
(-2.08)\end{array}$ \\
\hline $\begin{array}{l}\text { Inc_Relv[Pre-CF] } \\
{[F-\text { test }]}\end{array}$ & & $\begin{array}{l}0.67 * * * \\
{[28.85]}\end{array}$ & & $\begin{array}{l}0.67 * * * \\
{[47.05]}\end{array}$ \\
\hline $\begin{array}{l}\text { CF_Refs }[\text { Pre-CF] } \\
\text { [F-test] }\end{array}$ & & & $\begin{array}{l}0.24 * * \\
{[4.99]}\end{array}$ & $\begin{array}{l}0.24 * * \\
{[4.09]}\end{array}$ \\
\hline Observations & 159 & 156 & 159 & 156 \\
\hline Pseudo $R^{2}$ & $1.7 \%$ & $7.8 \%$ & $11.4 \%$ & $16.6 \%$ \\
\hline
\end{tabular}

Table 5 provides results for the estimation of equation 4, and is a supplementary test of Hypothesis $2 \mathrm{~b}$. Column (1) estimates a basic version of the equation; column (2) [column (3)] includes Inc_Relv [CF_Refs] variables; and column (4) estimates the full equation. I use a Tobit regression because the dependent variable ConstDissent\%, which measures constituent dissent percentage on standard $t$, is left-censored at zero.

Pre-CF is an indicator variable equal to one for SFAS 1 through SFAS 91. Inc_Relv is an indicator variable which identifies standards that increase accounting relevance, while $C F \_R e f s$ identifies the frequency of authoritative references to the $\mathrm{CF}$. The reference category is $C F$, an indicator variable (excluded from these regressions) equal to one for SFAS 92 through SFAS 160, so the coefficients on the standalone Inc_Relv and $C F \_R e f s$ variables reflects the CF regime. Inc_Relv[Pre-CF] (CF_Refs[Pre-CF]) represents the sum of the two Inc_Relv (CF_Refs) coefficients, and reflects the impact in the Pre-CF regime. Refer to Appendix 1 for variable definitions.

T-statistics are in brackets underneath each coefficient. Standard errors are heteroscedasticity-robust and clustered by combination. Significance levels based on two-tailed p-values: $(*) 10 \%$ level, $(* *) 5 \%$ level, $(* * *) 1 \%$ level 
TABLE 6. Detail on dissenting argument types on fair value standards

Panel A. Inside dissent on fair value standards in the Pre-CF and $C F$ regimes

\begin{tabular}{|c|c|c|c|c|c|c|}
\hline & \multirow[b]{3}{*}{ Pre-CF } & \multirow[b]{3}{*}{$C F$} & \multicolumn{4}{|c|}{ Difference in CF regime } \\
\hline & & & & Approx. & & \\
\hline & & & Difference & d.f. & t-stat & P-value \\
\hline Total fair value standards & 7 & 32 & & & & \\
\hline Total votes & 49 & 218 & & & & \\
\hline Total dissents & 16 & 18 & & & & \\
\hline Dissent $\%$ & $32.7 \%$ & $8.3 \%$ & & & & \\
\hline Total \# inside dissents & 3 & 11 & & & & \\
\hline$\%$ of dissent from inside & $18.8 \%$ & $61.1 \%$ & $42.3 \% * *$ & 33.62 & 2.73 & 0.010 \\
\hline Dissent $\%$ (excl. inside dissent) & $26.5 \%$ & $3.2 \%$ & & & & \\
\hline
\end{tabular}

Panel B. List of fair value standards in $C F$ regime with inside dissent

\begin{tabular}{|c|c|c|c|c|c|}
\hline SFAS & Title & $\begin{array}{l}\text { Total } \\
\text { Votes }\end{array}$ & $\begin{array}{c}\text { Total } \\
\text { Dissents }\end{array}$ & $<\mathrm{FV}$ & $>\mathrm{FV}$ \\
\hline 114 & Accounting by Creditors for Impairment of a Loan & 7 & 2 & 0 & 2 \\
\hline 115 & Accounting for Certain Investments in Debt and Equity Securities & 7 & 2 & 0 & 2 \\
\hline 125 & $\begin{array}{l}\text { Accounting for Transfers and Servicing of Financial Assets and } \\
\text { Extinguishments of Liabilities }\end{array}$ & 7 & 1 & 0 & 1 \\
\hline 140 & $\begin{array}{l}\text { Accounting for Transfers and Servicing of Financial Assets and } \\
\text { Extinguishments of Liabilities }\end{array}$ & 6 & 1 & 0 & 1 \\
\hline 146 & Accounting for Costs Associated with Exit or Disposal Activities & 7 & 1 & 0 & 1 \\
\hline 155 & Accounting for Certain Hybrid Financial Instruments & 7 & 1 & 0 & 1 \\
\hline 156 & Accounting for Servicing of Financial Assets & 7 & 1 & 0 & 1 \\
\hline 159 & The Fair Value Option for Financial Assets and Financial Liabilities & 7 & 2 & 0 & 2 \\
\hline
\end{tabular}

Panel A of Table 6 provides results for inside dissent on fair value standards in the Pre-CF and $C F$ regimes, and is used for testing Hypothesis 3. Panel B documents the standards on which I observe inside dissent in the $C F$ regime. I define a fair value standard as those with a Manual_inc_relv value greater than zero. Manual_inc_relv is an Allen and Ramanna (2013) metric that identifies standards that utilize fair value accounting.

In Panel A, column 2 (column 3) provides data for the Pre- $C F$ regime ( $C F$ regime). Total votes and Total dissents are hand-collected from each standard. When a FASB member abstains, it is not included as a vote within the "Total votes" above. The first percentage is Total dissents as a percentage of Total votes.

In Panel A, "Total \# inside dissents" represents the number of dissenting arguments explicitly calling for greater use of fair values, which for analytical purposes is limited to one argument per dissenter. For brevity, I omit data on all other dissenting arguments. The second percentage is the total number of inside dissenting arguments as a percentage of total dissents. The third (and final) percentage is the total number of dissents excluding those with inside dissenting arguments as a percentage of total votes. The difference (column 4) is calculated using a Welch's t-test for unpaired data with unequal variances. Column 5 provides the approximate degrees of freedom in the calculation of the difference, determined using the Welch formula.

Panel B provides the standards on which I observe inside dissent in the $C F$ regime. Dissenting arguments that explicitly call for lesser (greater) use of fair values are included in column 5 (6), and are limited to one fair value argument per dissenter.

Significance levels based on two-tailed p-values: (*) 10\% level, (**) 5\% level, (***) $1 \%$ level 
TABLE 7. Analysis of comment letter signatories and standard type

\begin{tabular}{|c|c|c|c|c|c|c|}
\hline \multirow[t]{2}{*}{$D V=P O S_{m \_}$Ordinal } & \multicolumn{2}{|c|}{$\begin{array}{c}\text { (1) } \\
\text { Full Sample }\end{array}$} & \multicolumn{2}{|c|}{$\begin{array}{c}(2) \\
\text { Inc_Relv }=1\end{array}$} & \multicolumn{2}{|c|}{$\begin{array}{c}(3) \\
C F \_R e f s>0\end{array}$} \\
\hline & $\begin{array}{l}\text { Mean } \\
\text { (z-stat) }\end{array}$ & $\begin{array}{l}\text { \% Change } \\
\text { in Odds }\end{array}$ & $\begin{array}{c}\text { Mean } \\
\text { (z-stat) }\end{array}$ & $\begin{array}{l}\text { \% Change } \\
\text { in Odds }\end{array}$ & $\begin{array}{c}\text { Mean } \\
\text { (z-stat) }\end{array}$ & $\begin{array}{l}\text { \% Change } \\
\text { in Odds }\end{array}$ \\
\hline FASB_Pre-CF & $\begin{array}{l}-0.44 * * \\
(-2.00)\end{array}$ & $-36 \%$ & & & & \\
\hline$F A S B \_C F$ & $\begin{array}{c}0.39 \\
(1.01)\end{array}$ & $48 \%$ & $\begin{array}{l}1.37 * \\
(1.83)\end{array}$ & $292 \%$ & $\begin{array}{c}0.62 \\
(1.40)\end{array}$ & $86 \%$ \\
\hline POS others_ordinal $_{1}$ & $\begin{array}{c}0.78 * * * \\
(5.36)\end{array}$ & $119 \%$ & $\begin{array}{c}1.00 * * * \\
(4.09)\end{array}$ & $172 \%$ & $\begin{array}{c}0.74 * * * \\
(4.74)\end{array}$ & $109 \%$ \\
\hline $\begin{array}{l}F A S B \_C F- \\
\text { FASB_Pre-CF } \\
\text { [Chi-square test] }\end{array}$ & $\begin{array}{l}0.83 * * \\
{[6.14]}\end{array}$ & $\mathrm{n} / \mathrm{a}$ & & & & \\
\hline Fixed effects? & $\begin{array}{r}\text { Yes; } \\
\text { (overa } \\
\text { Inc_Rel }\end{array}$ & $\begin{array}{l}\text { onsor } \\
\text { FE and } \\
\text { specific) }\end{array}$ & Yes; & onsor & $\begin{array}{r}\text { Yes; } \\
\text { (overa } \\
\text { Inc_Rel }\end{array}$ & $\begin{array}{l}\text { onsor } \\
\text { FE and } \\
\text { specific) }\end{array}$ \\
\hline Observations & & & & & & \\
\hline Pseudo $R^{2}$ & & & & & & \\
\hline
\end{tabular}

Table 7 provides results for the estimation of equation 6. Each observation reflects a comment letter sent by one of the following five sponsors: AICPA, FEI, IMA, CFA Institute, and AAA. I drop all comment letters where the related standard has fewer than two matched sponsor positions. I use an ordered logit regression because the dependent variable consists of five ordered categories. Column (1) includes the full sample of all remaining comment letters; column (2) includes only CLs on standards increasing accounting relevance; and column (3) includes only CLs on standards authoritatively referencing the CF. For brevity, I omit the estimated coefficients relating to both overall sponsor and Inc_Relv-specific fixed effects, as well as the estimated constants (i.e. the "cut-points"). The final value within each column provides the percentage change in odds for an increase in $P O S_{m_{-}}$Ordinal for a unit increase in the independent variable.

Refer to Appendix 1 for variable definitions. POS _ $_{-}$Ordinal represents the position of sponsor $m$ on each comment letter. FASB_Pre-CF $\left[F A S B \_C F\right]$ is an indicator variable equal to one when one of the signatories on the comment letter was later selected to the FASB in the Pre-CF [CF] regime. There are 22 [37] such letters in column (1); 1 [16] such letters in column (2); and 1 [25] such letters in column (3). I omit FASB_Pre-CF in columns (2) and (3) because there is only one related comment letter on which to estimate each coefficient. Results from a Chi-square test of the difference in the estimated coefficients on FASB_Pre-CF and $F A S B \_C F$ are included in column (1).

Z-statistics are in brackets underneath each coefficient. Standard errors are heteroscedasticity-robust and clustered by sponsor. Significance levels based on two-tailed p-values: $\left(^{*}\right) 10 \%$ level, $(* *) 5 \%$ level, $\left({ }^{* *}\right) 1 \%$ level 